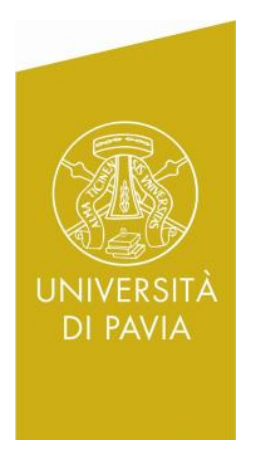

Department of Economics and Management DEM Working Paper Series

\title{
Monopolistic Competition, As You Like It
}

\author{
Paolo Bertoletti \\ (Università di Pavia) \\ Federico Etro \\ (Università Ca’ Foscari Venezia)
}

\# 142 (06-17)

Via San Felice, 5

I-27100 Pavia

http://epmq.unipv.eu/site/home.html

June 2017 


\title{
Monopolistic Competition, As You Like It
}

\author{
Paolo Bertoletti and Federico Etro ${ }^{1}$ \\ University of Pavia and Ca' Foscari University of Venice
}

June 2017

Keywords: Imperfect competition, Monopolistic competition, Asymmetric preferences, Heterogeneous firms

JEL Codes: D11, D43, L11

\begin{abstract}
We study imperfect and monopolistic competition with asymmetric preferences over a variety of goods provided by heterogeneous firms. We show how to compute equilibria through the Morishima elasticities of substitution. Simple pricing rules and closed-form solutions emerge under monopolistic competition when demands depend on common aggregators. This is the case for Generalized Additively Separable preferences (encompassing additive preferences and their Gorman-Pollak extensions), implicitly additive preferences and others. For applications to trade, with markups variable across goods of different quality, and to macroeconomics, with markups depending on aggregate variables, we propose specifications of indirectly additive, self-dual addilog and implicit CES preferences.
\end{abstract}

\footnotetext{
${ }^{1}$ We thank Lilia Cavallari, Mordecai Kurz, Florencio Lopez de Silanes, Mario Maggi, Ryoko Oki and Ina Simonovska for useful discussions on these themes. Correspondence. Paolo Bertoletti: Dept. of Economics and Management, University of Pavia, Via San Felice, 5, I-27100 Pavia, Italy. Tel: +390382986202, email: paolo.bertoletti@unipv.it. Federico Etro: Dept. of Economics, University of Venice Ca' Foscari, Sestiere Cannaregio, 30121, Fond.ta S.Giobbe 873, Venice, Italy. Tel: +390412349172, email: federico.etro@unive.it.
} 
Which prices should emerge in markets where firms sell differentiated goods? Such a basic question is at the core of modern economic theories that depart from the perfectly competitive paradigm by adopting the models of imperfect and monopolistic competition inspired by the works of Chamberlin (1933) and Robinson (1933). Unfortunately, most of these theories rely on a simplified model of competition with constant elasticity of substitution (CES) preferences based on Dixit and Stiglitz (1977, Section I), which delivers constant markups, either across countries and among firms in trade models (Krugman, 1980; Melitz, 2003) or over time in macroeconomic models (Blanchard and Kyotaki, 1987; Woodford, 2003). Only a few applications use more general but still symmetric preferences (Dixit and Stiglitz, 1977, Section II; Bertoletti and Etro, 2016), even when considering variable productivity across firms (as in Melitz and Ottaviano, 2008, Arkolakis et al., 2015, Bertoletti and Etro, 2017 or Parenti et al., 2017) and over time (as in Kimball, 1995, or Bilbiie et al., 2012). In an attempt to capture the features of monopolistic competition in the spirit of Chamberlin, ${ }^{2}$ in this paper we consider heterogeneous firms supplying genuinely different commodities. This suggests a richer way of thinking about markup variability across firms and markets as well as over time, which can be useful for applications to trade and macroeconomics.

We consider demand systems derived from preferences over a fixed number of different commodities that can be represented by any well-behaved utility functions. Each commodity is produced with a constant, idiosyncratic marginal cost. Our question is simply which choices should be made by firms in such a market. The natural starting point is the analysis of Cournot and Bertrand equilibria in which firms choose either their quantities or their prices taking as given the strategies of the competitors and the demand systems. We express the equilibrium pricing condition of a firm in terms of its market share and of the substitutability of its own product with respect to those sold by competitors. Substitutability is measured by the average of the Morishima Elasticities of Substitution, as rediscovered and formalized by Blackorby and Russell (1981). ${ }^{3}$ On this basis, we discuss how to solve for Cournot and Bertrand equilibria by computing the Morishima measures.

Then we move to monopolistic competition among a large number of firms where, in the spirit of Dixit and Stiglitz $(1977,1993)$, market shares are negligible and firms "perceive" demand elasticity as given by the average Morishima elasticity. This approach allows us to define an equilibrium even when demands depend in asymmetric ways on the strategies of the competitors. We exploit it to compare equilibria with monopolistic and imperfect competition for examples

\footnotetext{
${ }^{2}$ Chamberlin (1933) defined monopolistic competition with reference to factors affecting the shape of the demand curve, and certainly did not intend to limit his analysis to the case of symmetric goods. And he saw no discontinuity between its own market theory and "the theory of monopoly as familiarly conceived" (Chamberlin, 1937, p. 562), claiming inter alia that "monopolistic competition embraces the whole theory of monopoly. But it also looks beyond, and considers the interrelations, wherever they exist, between monopolists who are in some appreciable degree of competition with each other." (p. 571-2).

${ }^{3}$ The Morishima Elasticity of Substitution was originally proposed by Morishima (1967) in a book review written in Japanese.
} 
of homothetic preferences, namely when demands are derived from translog or generalized linear preferences.

Next we consider monopolistic competition for a wide type of preferences, the Generalized Additively Separable (GAS) preferences introduced by Pollak (1972). These include the large classes of directly and indirectly additive preferences (whose symmetric versions have been used respectively by Dixit and Stiglitz, 1977 and Bertoletti and Etro, 2017), and an additional class of preferences that we call Gorman-Pollak preferences after the contributions of Gorman (1970a, 1987) and Pollak (1972). With GAS preferences, the demand functions depend on a common aggregator of firm strategies. Intuition suggests that to take this aggregator as given while computing the elasticity of demand should be approximately correct when market shares are negligible. We show that this is indeed the case with GAS preferences. In addition, the equilibrium strategies do not depend on whether prices or quantities are chosen by the firms, implying that imperfectly competitive choices do actually "converge" to those of monopolistic competition when shares are negligible. This provides a simple approach to solve for the asymmetric equilibrium, and it allows the computation of prices in closed-form solution for a variety of examples. Actually, in the case of indirectly additive preferences, equilibrium pricing is independent across firms and the price of each firm depends on its marginal cost and product substitutability, and on the consumers' willingness to pay for its quality. The special case of constant markups that differ across goods emerges in case of "power" additive subutilities and with the more general and unexplored family of "self-dual addilog" preferences (see Houthakker, 1965). These examples, in which firms sell goods of different qualities at different markups in different markets, would be naturally useful for trade appplications.

The same approach to monopolistic competition can be extended to demand functions that depend on two common aggregators. Examples are provided by the asymmetric generalization of the preferences adopted by Melitz and Ottaviano (2008) to study international trade, or by the implicitly additive preferences due to Hanoch (1975). The latter nest the homothetic case used by the macroeconomic literature which has followed Kimball (1995), as well as the "implicit CES" preferences (Gorman, 1970a and 1970b, and Blackorby and Russell, 1981) which deliver markups common across goods that vary with the utility level and therefore consumers' expenditure. This is another unexplored specification which could be useful for the macroeconomic analysis of business cycle because provides a channel of propagation of aggregate shocks through markup variability. In conclusion, we remark that our approach to monopolistic competition can be further extended to other preferences delivering demand functions that depend on several aggregators.

Our work is related to different literatures. The analysis of Bertrand and Cournot competition with differentiated products is well known under quasilinear preferences (Vives, 1999). Our contribution is mainly in generalizing and reframing its setting in terms of the Morishima measures, whose role was 
introduced in Bertoletti and Etro (2016) in a symmetric environment. ${ }^{4}$ Few papers have analyzed monopolistic competition with asymmetric preferences. The original work of Dixit and Stiglitz (1977, Section III) touched on this topic only peripherally. The earliest treatement we are aware of is in the interesting work of Pascoa (1997), who focused on an example with Stone-Geary preferences and a continuum of goods. More recently, the trade literature with heterogeneous firms, started by Melitz (2003) and Melitz and Ottaviano (2008), has usually considered monopolistic competition with symmetric preferences for a continuum of goods. Only a few works have considered asymmetries to model quality differentials among goods (for instance Baldwin and Harrigan, 2012, Crozet, Head and Mayer, 2012 and Feenstra and Romalis, 2014), but retaining the CES structure of the Melitz model. We follow the spirit of this literature generalizing it to genuinely asymmetric preferences that deliver different markups.

Section 1 presents the basic model and the Cournot and Bertrand equilibria. It also introduces monopolistic competition as the market structure which arises when firm shares are small and competitors perceive demand elasticities as given by the average Morishima measures. Section 2 studies monopolistic competition under the generalized additive separability of preferences. Section 3 extends such an approach to the case of other separable preferences. Section 4 is the conclusion, and in the Appendix we show some example of "convergence" of imperfect competition equilibria when market shares are indeed negligible.

\section{A Model of Imperfect Competition}

We consider identical consumers with preferences over an exogenous (finite) number $n$ of commodities represented by the following direct and indirect utility functions:

$$
U=U(\mathbf{x}) \quad \text { and } \quad V=V(\mathbf{s}),
$$

where $\mathbf{x}$ is the $n$-dimensional vector of quantities and $\mathbf{s}=\mathbf{p} / E$ is the corresponding vector of prices normalized by income/expenditure $E$. We assume that preferences are well-behaved, and in particular that the utility maximizing choices are unique, interior $(\mathbf{x}>\mathbf{0})$ and characterized by the first-order conditions. Therefore, the inverse and direct (Marshallian) demand systems are delivered by the Hotelling-Wold's and Roy's identities:

$$
s_{i}(\mathbf{x})=\frac{U_{i}(\mathbf{x})}{\widetilde{\mu}(\mathbf{x})}, \quad x_{i}(\mathbf{s})=\frac{V_{i}(\mathbf{s})}{\mu(\mathbf{s})}
$$

where

$$
\widetilde{\mu}(\mathbf{x})=\sum_{j=1}^{n} U_{j}(\mathbf{x}) x_{j}, \quad \mu(\mathbf{s})=\sum_{j=1}^{n} V_{j}(\mathbf{s}) s_{j}
$$

\footnotetext{
${ }^{4}$ See Etro $(2016,2017)$ for applications to macroeconomics and trade in a symmetric environment.
} 
and $U_{i}$ and $V_{i}$ denote marginal utilities, $i=1, \ldots, n$. Here $\widetilde{\mu}$ is the marginal utility of income times the expenditure level, and $|\mu(\mathbf{s})|=\widetilde{\mu}(\mathbf{x}(\mathbf{s}))$, as can be verified by "adding up" the market shares $b_{j}=s_{j} x_{j}$.

Firm $i$ produces good $i$ at the marginal cost $c_{i}$ and obtains per-consumer variable profits given by: ${ }^{5}$

$$
\pi_{i}=\left(p_{i}-c_{i}\right) x_{i} .
$$

We begin from the case in which each firm correctly perceives its demand function and chooses its optimal strategy. In the tradition of industrial organization we have to consider two separate equilibria, where each firm simultaneously chooses either its production level (Cournot competition) or its price (Bertrand competition).

\subsection{Cournot competition}

Let us start considering firms that choose their quantities on the basis of the inverse demand functions $s_{i}(\mathbf{x})$ in (2). Correctly anticipating the quantities $\mathbf{x}_{-i}^{\prime}=\left[x_{1}, . ., x_{i-1}, x_{i+1}, . ., x_{n}\right]$ produced by the competitors, each firm $i$ chooses $x_{i}$ to equate its marginal revenue to its marginal cost $c_{i}$. The relevant "individual marginal revenue" of firm $i$ is $M R_{i}=\partial\left(p_{i} x_{i}\right) / \partial x_{i}$, where $p_{i}(\mathbf{x})=s_{i}(\mathbf{x}) E$. It can be written as:

$$
\begin{aligned}
M R_{i} & =\frac{\left[U_{i}(\mathbf{x})+U_{i i}(\mathbf{x}) x_{i}\right] \widetilde{\mu}(\mathbf{x})-U_{i}(\mathbf{x}) x_{i}\left[U_{i}(\mathbf{x})+\sum_{j=1}^{n} U_{j i}(\mathbf{x}) x_{j}\right]}{\widetilde{\mu}(\mathbf{x})^{2}} E \\
& =p_{i}(\mathbf{x})\left[1-s_{i}(\mathbf{x}) x_{i}-\sum_{j=1}^{n} \epsilon_{i j}(\mathbf{x}) s_{j}(\mathbf{x}) x_{j}\right]
\end{aligned}
$$

where the (gross) Morishima Elasticity of Complementarity (MEC) between varieties $i$ and $j$ is defined as: ${ }^{6}$

$$
\epsilon_{i j}(\mathbf{x})=-\frac{\partial \ln \left\{s_{i}(\mathbf{x}) / s_{j}(\mathbf{x})\right\}}{\partial \ln x_{i}}=\frac{U_{j i}(\mathbf{x}) x_{i}}{U_{j}(\mathbf{x})}-\frac{U_{i i}(\mathbf{x}) x_{i}}{U_{i}(\mathbf{x})} .
$$

These inverse measures of substitutability depend on preferences and not on the specific utility functions which are chosen to represent them. Since substitutability can change among goods, let us compute the weighted average of the MECs for good $i$ with respect to all the other goods $j$, with weights based on the expenditure shares $b_{j}(\mathbf{x}) \equiv s_{j}(\mathbf{x}) x_{j}$, namely:

$$
\bar{\epsilon}_{i}(\mathbf{x})=\sum_{j \neq i}^{n} \epsilon_{i j}(\mathbf{x}) \frac{b_{j}(\mathbf{x})}{1-b_{i}(\mathbf{x})}
$$

\footnotetext{
${ }^{5}$ Since expenditure is assumed exogenous and independent from profits, no explicit role is left here to play for the size of the market or for possible fixed costs (but see the extension to entry sketched in Section 1.5).

${ }^{6}$ See Blackorby and Russell (1981), and their application to the case of symmetric preferences in Bertoletti and Etro (2016). The larger is $\epsilon_{i j}$ the smaller is the possibility of good $j$ to substitute for good $i$. Notice that $\epsilon_{i i}=0$ and that in general $\epsilon_{i j} \neq \epsilon_{j i}$ for $i \neq j$.
} 
It is immediate to verify that the marginal revenue can be rewritten as $M R_{i}=p_{i}(\mathbf{x})\left[1-b_{i}(\mathbf{x})\right]\left[1-\bar{\epsilon}_{i}(\mathbf{x})\right]$, and that the equilibrium quantities satisfy the system:

$$
p_{i}(\mathbf{x})=\frac{c_{i}}{1-\epsilon_{i}^{C}(\mathbf{x})} \quad \text { for } i=1,2, \ldots, n,
$$

where the left hand side comes from the inverse demand given in (2) and the right hand side depends on:

$$
\epsilon_{i}^{C}(\mathbf{x})=b_{i}(\mathbf{x})+\left[1-b_{i}(\mathbf{x})\right] \bar{\epsilon}_{i}(\mathbf{x}) .
$$

Here $\epsilon_{i}^{C}$ is an increasing function of the market share of firm $i$ and of its average Morishima elasticity $\bar{\epsilon}_{i}$, and must be smaller than unity. ${ }^{7}$ Intuitively, a firm's markup is higher when it supplies a good that is on average less substitutable with the other goods $\left(\right.$ high $\bar{\epsilon}_{i}$ ), and its market share is larger (high $b_{i}$ ). The Cournot equilibrium system (7) is operational, in the sense that for given preferences and cost distribution one can directly solve for the Cournot quantities with standard computational methods and then obtain the equilibrium prices. ${ }^{8}$

Let us consider the Cournot equilibria in the well-known example of CES preferences with utility $U=\sum_{j} x_{j}^{1-\epsilon}$, where $\epsilon \in[0,1)$ is a parameter corresponding to a common and constant MEC. Closed form solutions emerge in few cases cases. For instance, in case of a Cournot duopoly we can solve explicitly for:

$$
x_{i}^{C}=\frac{c_{j}^{1-\epsilon}(1-\epsilon) E}{\left(c_{i}^{1-\epsilon}+c_{j}^{1-\epsilon}\right)^{2} c_{i}^{\epsilon}} \quad \text { and } p_{i}^{C}=\frac{c_{i}}{1-\epsilon}\left[1+\left(\frac{c_{j}}{c_{i}}\right)^{1-\epsilon}\right] .
$$

The price of each firm is increasing in its cost (though less than proportionally) and in the relative cost of the other firm, while it is independent from income. Remarkably, when goods are perfect substitutes $(\epsilon=0)$ the equilibrium price is the sum of the marginal costs. ${ }^{9}$ In a perfectly symmetric setting with common cost $c$ we obtain:

$$
x^{C}=\frac{(n-1)(1-\epsilon) E}{n^{2} c} \quad \text { and } \quad p^{C}=\frac{n c}{(n-1)(1-\epsilon)}
$$

for any firm.

\footnotetext{
${ }^{7}$ Throughout this work we assume that the first-order condition for profit maximization characterizes firm behaviour. Of course, existence and unicity of the solution require that the demand system satisfies a number of regularity conditions (for a related discussion see Vives, 1999, Ch. 6).

${ }^{8}$ Analytical progress is possible in the case of two commodities, where $p_{i}\left(1-\epsilon_{i j}\right) b_{j}=c_{i}$ and therefore:

$$
\frac{x_{1}}{x_{2}}=\frac{c_{1}}{c_{2}} \frac{1-\epsilon_{21}\left(x_{1}, x_{2}\right)}{1-\epsilon_{12}\left(x_{1}, x_{2}\right)},
$$

which in principle allows to solve for the duopoly equilibrium quantities.

${ }^{9} \mathrm{With}$ homogenous goods we can solve for the oligopoly equilibrium obtaining $p_{i}^{C}=n \bar{c} /(n-$ 1 ), where $\bar{c}$ is the industry average cost.
} 


\subsection{Bertrand competition}

Consider now firms that choose their prices on the basis of the direct demand $x_{i}(\mathbf{s})$ in (2), while correctly anticipating the prices of the competitors $\mathbf{s}_{-i}^{\prime}=$ $\left[s_{1}, . ., s_{i-1}, s_{i+1}, . ., s_{n}\right]$. The elasticity of the Marshallian direct demand of firm $i$ can be computed as:

$$
\left|\frac{\partial \ln x_{i}}{\partial \ln p_{i}}\right|=-\frac{s_{i}}{x_{i}(\mathbf{s})} \frac{V_{i i}(\mathbf{s}) \mu(\mathbf{s})-V_{i}(\mathbf{s})\left[V_{i}(\mathbf{s})+\sum_{j=1}^{n} V_{j i}(\mathbf{s}) s_{j}\right]}{\mu(\mathbf{s})^{2}} .
$$

Consider the (gross) Morishima Elasticity of Substitution (MES) between goods $i$ and $j:{ }^{10}$

$$
\varepsilon_{i j}(\mathbf{s})=-\frac{\partial \ln \left\{x_{i}(\mathbf{s}) / x_{j}(\mathbf{s})\right\}}{\partial \ln s_{i}}=\frac{s_{i} V_{j i}(\mathbf{s})}{V_{j}(\mathbf{s})}-\frac{s_{i} V_{i i}(\mathbf{s})}{V_{i}(\mathbf{s})},
$$

which again depends on preferences and not on their specific representations, and compute the weighted average:

$$
\bar{\varepsilon}_{i}(\mathbf{s}) \equiv \sum_{j \neq i}^{n} \varepsilon_{i j}(\mathbf{s}) \frac{b_{j}(\mathbf{s})}{\left(1-b_{i}(\mathbf{s})\right)}
$$

where, with a little abuse of notation, $b_{j}(\mathbf{s})=s_{j} x_{j}(\mathbf{s})$ is now the expenditure share of firm $i$ as a function of the normalized prices.

We can now rewrite the demand elasticity $\left|\partial \ln x_{i} / \partial \ln p_{i}\right|$ as:

$$
\varepsilon_{i}^{B}(\mathbf{s})=b_{i}(\mathbf{s})+\left[1-b_{i}(\mathbf{s})\right] \bar{\varepsilon}_{i}(\mathbf{s}),
$$

which needs to be larger than 1 to define the Bertrand equilibrium through the following system: ${ }^{11}$

$$
p_{i}=\frac{\varepsilon_{i}^{B}(\mathbf{s}) c_{i}}{\varepsilon_{i}^{B}(\mathbf{s})-1} \quad \text { for } i=1,2, . ., n .
$$

Firms set higher markups if their goods are on average less substitutable than those of competitors (low $\bar{\varepsilon}_{i}$ ) and their market shares larger (high $b_{i}$ ). The system (14) allows one to directly compute all Bertrand equilibrium prices for given costs and preferences.

It is well known that the Bertrand prices do not coincide with those obtained under competition in quantities. As an example, consider again CES preferences, whose indirect utility can be written as $V=\sum_{i} s_{i}^{1-\varepsilon}$. The parameter $\varepsilon>1$ corresponds to the constant and symmetric MES and is the reciprocal

\footnotetext{
${ }^{10}$ See Blackorby and Russell (1981) and Blackorby et al. (2007). The higher is $\varepsilon_{i j}$ the greater is the possibility of good $j$ to substitute for good $i$. Notice that $\varepsilon_{i i}=0$ and that in general $\varepsilon_{i j} \neq \varepsilon_{j i}$ for $i \neq j$.

${ }^{11}$ Again, for the existence and unicity of the equilibrium the demand system has to satisfy a number of regularity conditions (see Vives, 1999, Ch. 6).
} 
of the MEC parameter $\epsilon=1 / \varepsilon$ in the previous representation of the same preferences. ${ }^{12}$ In this case we can derive an implicit expression for the best response functions:

$$
p_{i}=c_{i}\left[\frac{\varepsilon}{\varepsilon-1}+\frac{p_{i}^{1-\varepsilon}}{(\varepsilon-1) \sum_{j \neq i} p_{j}^{1-\varepsilon}}\right],
$$

which shows the strategic complementarity among price choices. In a Bertrand duopoly this gives:

$$
p_{i}=\frac{c_{i}\left[\varepsilon+\left(\frac{p_{j}}{p_{i}}\right)^{\varepsilon-1}\right]}{\varepsilon-1},
$$

which has no closed-form solution but implies markups different from the Cournotian. ${ }^{13}$ The case of a fully symmetric oligopoly, instead, provides the explicit solution for the Bertrand equilibrium price:

$$
p^{B}=\frac{[(n-1) \varepsilon+1] c}{(n-1)(\varepsilon-1)},
$$

which is below the Cournot equilibrium price and approaches the marginal cost for perfect substitutability $(\varepsilon \rightarrow \infty)$.

\subsection{Monopolistic competition}

The remaining part of this paper is dedicated to analyze monopolistic competition. There are different ways to make sense of this concept but, in the spirit of Dixit and Stiglitz's (1993) reply to Yang and Heidra (1993), we interpret monopolistic competition as the result of having firms that correctly perceive market shares as negligible. In fact, what Dixit and Stiglitz (1977) did in their symmetric setting amounts to neglect any term of order $1 / n$ in the demand elasticities, where $n$ is a number of firms assumed sufficiently large to make the omitted terms small. Similarly, in our setting, when there are many goods we should expect the consumers to spread their expenditure if preferences are wellbehaved and not too asymmetric, so that the market shares should be small for all goods. ${ }^{14}$ On this basis, our previous results suggest to approximate the relevant demand elasticities with the corresponding averages of the Morishima measures.

Accordingly, we will consider as monopolistically competitive an environment where market shares are negligible, that is $b_{i} \approx 0$ for any $i=1, . ., n$, and

\footnotetext{
${ }^{12}$ It is worth mentioning that this special result is due to the "strong self-duality" (see Section 2.3 below) of CES preferences, and does not generally hold.

${ }^{13}$ The Bertand relative price $z^{B}=p_{i}^{B} / p_{j}^{B}$ is the solution to the equation:

$$
z^{\varepsilon}+\varepsilon z-\widehat{c} z^{1-\varepsilon}-\widehat{c} \varepsilon=0
$$

where $\widehat{c}=c_{i} / c_{j}$. Notice that in a Cournot duopoly $z^{C}=\widehat{c}^{\epsilon}$, but this can be a solution of the previous equation only if $\widehat{c}=1$. Thus quantity and price competition deliver different relative prices.

${ }^{14}$ Sufficient conditions on preferences to deliver this result are studied in Vives (1987).
} 
where firms, correctly anticipating the value of actual demands, "perceive" the relevant elasticities as given by the average Morishima measures. This approach actually leads to two approximations according to whether we refer either to quantity or to price competition. In the first case we approximate (7) by using the expression:

$$
p_{i}(\mathbf{x})=\frac{c_{i}}{1-\bar{\epsilon}_{i}(\mathbf{x})} \quad \text { for } i=1,2, . ., n .
$$

In the second case we approximate (14) by:

$$
p_{i}=\frac{\bar{\varepsilon}_{i}(\mathbf{s}) c_{i}}{\bar{\varepsilon}_{i}(\mathbf{s})-1} \quad \text { for } i=1,2, . ., n .
$$

These simplified systems have be solved to derive the prices and quantities which arise in the monopolistic competition equilibrium (that should imply negligible market shares). Once we depart from symmetry this is still a formidable task, but in the next sections we will consider several types of asymmetric preferences for which explicit solutions can be actually derived.

We can learn something more about this approach to monopolistic competition by considering the cross demand elasticities. They can be computed as:

$$
\begin{aligned}
\frac{\partial \ln p_{j}(\mathbf{x})}{\partial \ln x_{i}} & =\frac{U_{j i}(\mathbf{x}) x_{i}}{U_{j}(\mathbf{x})}-\sum_{h=1}^{n} \frac{U_{h i}(\mathbf{x}) x_{i}}{U_{h}(\mathbf{x})} b_{h}(\mathbf{x}) \\
& =\epsilon_{i j}(\mathbf{x})-\bar{\epsilon}_{i}(\mathbf{x})+b_{i}(\mathbf{x}) \bar{\epsilon}_{i}(\mathbf{x}), \\
\frac{\partial \ln x_{j}(\mathbf{s})}{\partial \ln p_{i}} & =\varepsilon_{i j}(\mathbf{s})-\left|\frac{\partial \ln x_{i}(\mathbf{s})}{\partial \ln p_{i}}\right| \\
& =\varepsilon_{i j}(\mathbf{s})-\bar{\varepsilon}_{i}(\mathbf{s})-b_{i}(\mathbf{s})\left(1-\bar{\varepsilon}_{i}(\mathbf{s})\right) .
\end{aligned}
$$

When shares are indeed negligible the cross effects should be perceived as negligible too whenever the differences $\epsilon_{i j}-\bar{\epsilon}_{i}$ and $\varepsilon_{i j}-\bar{\varepsilon}_{i}$ are small and the perceived own elasticities are not very large. Apparently, this is the case that Dixit and Stiglitz (1993) had in mind, and we expect it to apply to the typical monopolistic competition equilibrium with positive markups. Notice that the former condition is satisfied in any equilibrium of a symmetric environment. However, both conditions might be violated in our asymmetric setting: in similar cases the perceived cross demand elasticities can be large, and associated to a large own demand elasticity and therefore to small equilibrium markups. In other words, it can happen that goods are perceived as highly substitutable and that monopolistic competition pricing approximates marginal cost pricing, as we will see in one of the following examples. ${ }^{15}$

\footnotetext{
${ }^{15}$ Notice that, in general, the value of these cross demand elasticities need not be negligible in a strategic setting. In fact, if they were null there would be no reason for strategic interaction and we could think of those producers as "isolated monopolists".
} 


\subsection{Examples with homothetic preferences}

Benassy (1996) studies examples of monopolistic competition with symmetric homothetic preferences. ${ }^{16}$ Here we are concerned with the more general case of asymmetric preferences. Let us normalize the indirect utility function to be:

$$
V=\frac{E}{P(\mathbf{p})}=\frac{1}{P(\mathbf{s})},
$$

where $P$ is homogeneous of degree 1 and, as is well known, is a fully-fledged price index. The Roy's identity delivers direct demands and market shares:

$$
x_{i}=\frac{P_{i}(\mathbf{s})}{P(\mathbf{s})} \quad \text { and } \quad b_{i}=\frac{s_{i} P_{i}(\mathbf{s})}{P(\mathbf{s})},
$$

which are homogeneous respectively of degree -1 and 0 . This allows us to compute the MES as:

$$
\varepsilon_{i j}(\mathbf{s})=\frac{s_{i} P_{j i}(\mathbf{s})}{P_{j}(\mathbf{s})}-\frac{s_{i} P_{i i}(\mathbf{s})}{P_{i}(\mathbf{s})},
$$

which is homogeneous of degree 0 , being the difference of two functions that are both homogeneous of that degree. The fact that both the average MES $\bar{\varepsilon}_{i}$ and the market share $b_{i}$ must be homogeneous of degree zero implies immediately that pricing is independent from income. ${ }^{17}$ Similar results can be derived starting from the direct utility (which can be written as a consumption index) and using the inverse demand system and the average MEC to study quantity competition.

Translog preferences To illustrate, let us consider the homothetic translog preferences (Christensen et al., 1975) represented by the following price index:

$$
P(\mathbf{s})=\exp \left[\ln \alpha_{0}+\sum_{i} \alpha_{i} \ln s_{i}+\frac{1}{2} \sum_{i} \sum_{j} \beta_{i j} \ln s_{i} \ln s_{j}\right],
$$

where we assume without loss of generality $\beta_{i j}=\beta_{j i}$, and we need $\sum_{i} \alpha_{i}=1$ and $\sum_{j} \beta_{i j}=0$ to satisfy the linear homogeneity of $P$ (Feenstra, 2003 uses a symmetric version of these preferences). The direct demand for good $i$ is:

$$
x_{i}(\mathbf{s})=\frac{P_{i}(\mathbf{s})}{P(\mathbf{s})}=\frac{\alpha_{i}+\sum_{j} \beta_{i j} \ln s_{j}}{s_{i}},
$$

\footnotetext{
${ }^{16}$ Also see Feenstra $(2003,2014)$, who considers the case of heterogeneous firms with a symmetric version of the so-called "quadratic mean of order $r$ " (QMOR) preferences, which include the well-known translog specification.

${ }^{17}$ Moreover, when the homothetic preferences are symmetric, Morishima elasticities and markups in a symmetric equilibrium can be at most a function of the number of goods. While this result has been used elsewhere (for instance in Bilbiie et al., 2012), we are not aware of a previous proof. We are thankful to Mordecai Kurz for pointing this out.
} 
which delivers the market share $b_{i}=\alpha_{i}+\sum_{j} \beta_{i j} \ln s_{j}$. Profits of firm $i$ are then given by:

$$
\pi_{i}=\frac{\left(p_{i}-c_{i}\right)\left[\alpha_{i}+\sum_{j} \beta_{i j} \ln \left(p_{j} / E\right)\right] E}{p_{i}},
$$

whose direct maximization provides the Bertrand equilibrium conditions:

$$
p_{i}=c_{i}\left(1+\frac{b_{i}}{\beta_{i}}\right)
$$

where the positiveness of $\beta_{i} \equiv-\beta_{i i}$ is necessary to ensure $\varepsilon_{i}^{B}=1+\beta_{i} / b_{i}>1 .^{18}$

We can obtain the same result, as well as the monopolistic competition equilibrium by deriving the Morishima elasticity between goods $i$ and $j$ as:

$$
\varepsilon_{i j}=1+\frac{\beta_{i}}{b_{i}}+\frac{\beta_{j i}}{b_{j}}
$$

so that the average MES is:

$$
\bar{\varepsilon}_{i}=\sum_{j \neq i}^{n} \varepsilon_{i j} \frac{b_{j}}{1-b_{i}}=1+\frac{\beta_{i}}{\left(1-b_{i}\right) b_{i}} .
$$

This allows one to get (22) from (18), and to express the monopolistic competition prices as:

$$
p_{i}=c_{i}\left[1+\frac{\left(1-b_{i}\right) b_{i}}{\beta_{i}}\right]
$$

(that are smaller than the Bertrand prices, as expected). ${ }^{19}$ Moreover, when the market shares are indeed negligible $\left(b_{i} \approx 0\right)$, the average MES is large, goods are highly substitutable and the price must be close to marginal cost $\left(\widehat{p}_{i} \approx c_{i}\right)$.

Generalized linear preferences Let us now discuss an example of asymmetric homothetic preferences due to Diewert (1971). Suppose that preferences

${ }^{18}$ We can rewrite $(22)$ as:

$$
p_{i}=c_{i}\left(1+\frac{\alpha_{i}+\sum_{j \neq i} \beta_{i j} \ln p_{j}}{\beta_{i}}-\ln p_{i}\right) .
$$

Taking logs and approximating for small markups we get:

$$
\left[\begin{array}{c}
\ln p_{1}^{B} \\
\ln p_{2}^{B} \\
\ddot{\ln p_{n}^{B}}
\end{array}\right] \approx\left[\begin{array}{cccc}
2 & -\frac{\beta_{12}}{\beta_{1}} & . . & -\frac{\beta_{1 n}}{\beta_{1}} \\
-\frac{\beta_{21}}{\beta_{2}} & 2 & . . & -\frac{\beta_{2 n}}{\beta_{2}} \\
\ddot{\beta_{n 1}} & -\ddot{\beta_{n 2}} & . . & . . \\
-\frac{.}{\beta n} & 2
\end{array}\right]^{-1}\left[\begin{array}{c}
\ln c_{1}+\frac{\alpha_{1}}{\beta_{1}} \\
\ln c_{2}+\frac{\alpha_{2}}{\beta_{2}} \\
. \\
\ln c_{n}+\frac{\alpha_{n}}{\beta_{n}}
\end{array}\right] .
$$

\footnotetext{
${ }^{19}$ Under full symmetry, the equilibrium prices correspond to those reported in Bertoletti and Etro (2016), whereas demand parameters are endogenous as in Feenstra (2003).
} 
can be represented by the following direct utility/consumption index:

$$
U=\sqrt{\mathbf{x}}^{\prime} \mathbf{A} \sqrt{\mathbf{x}}=\sum_{i} \sum_{j} \sqrt{x_{i}} a_{i j} \sqrt{x_{j}}
$$

where, without loss of generality, we can take the matrix $\mathbf{A}$ to be symmetric. To satisfy the standard regularity conditions we assume that $a_{i j} \geq 0$ for any $i, j$ (notice that parameters $a_{i i}, i=1, . ., n$ have no impact on the Hessian $D^{2} U$ ). Here we obtain $U_{i}=\sum_{j} a_{i j} \sqrt{x_{j}} / \sqrt{x_{i}}$ and $\widetilde{\mu}=U$, with market shares $b_{i}=$ $\left(\sqrt{x_{i}} \sum_{j} a_{i j} \sqrt{x_{j}}\right) / U(\mathbf{x})$. Since the MECs can be computed as:

$$
\epsilon_{i j}=\frac{1}{2}\left[1+\frac{a_{i j} \sqrt{x_{i}}}{\sum_{h} a_{j h} x_{h}^{\frac{1}{2}}}-\frac{a_{i i} \sqrt{x_{i}}}{\sum_{h} a_{i h} x_{h}^{\frac{1}{2}}}\right],
$$

we obtain the average MEC:

$$
\bar{\epsilon}_{i}=\frac{1}{2}\left\{1-\frac{a_{i i} \sqrt{x_{i}}}{\sum_{h} a_{i h} \sqrt{x_{h}}}+\frac{b_{i}-a_{i i} x_{i} / U(\mathbf{x})}{1-b_{i}}\right\},
$$

which allows us determine the equilibrium conditions. ${ }^{20} \bar{\epsilon}_{i}$ is strictly positive for every good, implying positive markups, unless $a_{i j}=0$ for any $i \neq j$ (in which case commodities would be perfect substitutes).

A simple case emerges when $a_{i i}=0$ for any $i$, which implies $\bar{\epsilon}_{i}=1 /\left[2\left(1-b_{i}\right)\right]$. This allows us to express Cournot prices as:

$$
p_{i}=\frac{2 c_{i}}{1-2 b_{i}}
$$

and the monopolistic competition prices as:

$$
p_{i}=\frac{2\left(1-b_{i}\right) c_{i}}{1-2 b_{i}} .
$$

The markups do not vanish when the market shares become negligible, but rather converge to twice the marginal cost: indeed we reach $\widehat{p}_{i} \approx 2 c_{i}$ when $b_{i} \approx 0$.

\subsection{Outside goods and endogenous entry}

Concluding this section we mention briefly two important extensions of our setting that are conceptually straightforward but can be useful for general equilibrium applications. First, one can add a good representing the outside economy. Pricing within the monopolistically competitive sector carries on unchanged after imposing independent pricing for the outside good (typically marginal cost pricing if perfect competition holds in that sector) and taking this into account

\footnotetext{
${ }^{20}$ Notice that in the special, fully symmetric case with $a_{i j}=a>0$ for $i, j=1, \ldots, n$, one gets $\bar{\epsilon}_{i}=1 / 2$ as in Bertoletti and Etro (2016).
} 
in the computation of the average Morishima elasticity. Instead, solving for Cournot or Bertrand competition is more complex in the presence of an outside good (see also d'Aspremont and Dos Santos Ferreira, 2016).

Second, one can consider endogenous free entry in the same spirit as Pascoa (1997) and Melitz (2003). Given an ex-ante probability distribution over parameters indexing the goods to be produced (concerning both costs and preferences), $n$ firms would enter the market until the expected profits cover the entry cost. This would leave unchanged the competition stage whenever costs and market size attract a number of firms large enough to justify the assumption of small market shares.

\section{Monopolistic competition with GAS prefer- ences}

In this section we explore preferences that generate direct demand functions that depend on the own price and one common aggregator of all prices or, equivalently, inverse demand functions that depend on the own quantity and one common aggregator of all the quantities. Pollak (1972) termed these as generalized additively separable (GAS) preferences and showed that they encompass three main classes: ${ }^{21}$ the directly and indirectly additive preferences (Houthakker, 1960), whose symmetric versions have been used to model monopolistic competition respectively by Dixit and Stiglitz (1977) and Bertoletti and Etro (2017), ${ }^{22}$ and what we call "Gorman-Pollak preferences", that have been discussed by Gorman (1970a, 1987) and Pollak (1972) but, as far as we know, never applied to the analysis of monopolistic competition (nor to other issues). ${ }^{23}$ In this environment we show that an equilibrium of monopolistic competition can be identically defined starting from either price or quantity competition and having firms to perceive as given the value of the common aggregator of individual behaviors. This approach is entirely consistent with that adopted by Dixit and Stiglitz (1977) who suggested, in a setting with symmetric and directly additive preferences, to neglect the impact of an individual firm on the marginal utility of income (the relevant aggregator in their setting).

Pollak (1972) defined Generalized Additively Separable (GAS) preferences as those exhibiting demand functions that can be written as:

$$
s_{i}=s_{i}\left(x_{i}, \xi(\mathbf{x})\right) \text { and } \quad x_{i}=x_{i}\left(s_{i}, \rho(\mathbf{s})\right),
$$

where $\partial s_{i} / \partial x_{i}, \partial x_{i} / \partial p_{i}<0$ and $\xi(\mathbf{x})$ and $\rho(\mathbf{s})$ are common functions ("aggregators") of respectively quantities and prices. Notice that $s_{i}=x_{i}^{-1}\left(x_{i} ; \xi(\mathbf{x})\right)$ is the partial inverse of $x_{i}(\cdot)$ with respect to its first argument, and that $\xi(\mathbf{x})=\rho(\mathbf{s}(\mathbf{x}))$.

\footnotetext{
${ }^{21}$ Gorman (1970) and Pollak (1972) show that there are also other families of GAS preferences, strictly related to the CES case: we will refer to them below.

${ }^{22}$ Also see Mrázová and Neary (2017).

${ }^{23}$ Gorman (1987) writes: "I have not seen this system tried, which is a pity, since it is easily understood, is related to a leading theoretical model, and would be very useful should it fit."
} 
It turns out that GAS preferences provide an ideal setting to study monopolistic competition, since we can naturally define it as the environment in which each firm correctly anticipates the value of the aggregators $\rho$ and $\xi$, but takes ("perceives") them as given while choosing its strategy to maximize profits:

$$
\pi_{i}=\left(s_{i} E-c_{i}\right) x_{i}\left(s_{i}, \rho\right)=\left(s_{i}\left(x_{i}, \xi\right) E-c_{i}\right) x_{i} .
$$

It is important to stress that in this case the price and quantity equilibria of monopolistic competition do coincide. Since the "perceived" inverse demand of a commodity is just the inverse of the "perceived" direct demand, the corresponding elasticities $\epsilon_{i}$ and $\varepsilon_{i}$ are simply related by the condition $\varepsilon_{i}=1 / \epsilon_{i}$ (as in a monopoly).

The first-order conditions ${ }^{24}$ for profit maximization of (28) taking as given either $\rho$ or $\xi$ define a system of pricing or production rules, say:

$$
p_{i}=\underline{p}_{i}\left(c_{i}, \rho\right) \quad \text { and } \quad x_{i}=\underline{x}_{i}\left(c_{i}, \xi\right) .
$$

These rules, together with the budget constraint $\sum_{j} p_{j} x_{j}=E$ and the assumption that firms correctly anticipate the actual demands, can be used to derive the equilibrium value of the aggregators as a function of the cost vector $\mathbf{c}$ and of income $E$, and therefore the equilibrium prices $\widehat{p}_{i}(\mathbf{c}, E)$ and quantities $\widehat{x}_{i}(\mathbf{c}, E)$. In Appendix A we prove that, when preferences are of the GAS type and the market shares become negligible, the perceived demand elasticity does approximate the average Morishima measure. Accordingly, the monopolistic competition equilibrium where firms take aggregators as given approximates the imperfect competition equilibria of Section 1, which in this sense do "converge".

To illustrate our solution concept we will now use it in a number of examples of preferences of the GAS type. In contrast to what happens in the case of the equilibria described before, it turns out that in several cases we can obtain closed-form solutions.

\subsection{Directly additive preferences}

Preferences are directly additive when they can be represented by the direct utility:

$$
U=\sum_{j=1}^{n} u_{j}\left(x_{j}\right)
$$

where the sub-utility functions $u_{j}$ are increasing and concave. The inverse demand system is given by

$$
s_{i}\left(x_{i}, \xi(\mathbf{x})\right)=\frac{u_{i}^{\prime}\left(x_{i}\right)}{\xi(\mathbf{x})},
$$

where $\xi=\widetilde{\mu}=\sum_{j} x_{j} u_{j}^{\prime}$ and $x_{i}\left(s_{i}, \rho\right)=u_{i}^{\prime-1}\left(s_{i} \xi\right)$. These preferences clearly belong to the GAS type, and were originally used by Dixit and Stiglitz (1977)

\footnotetext{
${ }^{24}$ Of course it is also necessary that the second-order conditions are satisfied, i.e., basically that the "perceived" marginal revenues are decreasing.
} 
in the symmetric version with $u_{j}(x)=u(x)$ for all $j .{ }^{25}$ We can express the profits of each firm $i$ as:

$$
\pi_{i}=\left[\frac{u_{i}^{\prime}\left(x_{i}\right) E}{\xi}-c_{i}\right] x_{i}
$$

Let us define the elasticity of the marginal subutility $\epsilon_{i}(x) \equiv-x u_{i}^{\prime \prime}(x) / u_{i}^{\prime}(x)$, which corresponds to the elasticity of the inverse demand $s_{i}(x, \xi)$ for given $\xi$. $\epsilon_{i}$ is also the MEC $\epsilon_{i j}$ between good $i$ and any other good $j \neq i$, therefore it coincides also with the average MEC $\bar{\epsilon}_{i}$ discussed in Section 1. The profitmaximizing condition ${ }^{26}$ with respect to $x_{i}$, taking $\xi$ as given, is:

$$
u_{i}^{\prime \prime}\left(x_{i}\right) x_{i} E+u_{i}^{\prime}\left(x_{i}\right) E=\xi c_{i},
$$

and it can be rearranged in the pricing conditions:

$$
p_{i}\left(x_{i}\right)=\frac{c_{i}}{1-\epsilon_{i}\left(x_{i}\right)}, \quad i=1,2, \ldots, n,
$$

where $p_{i}\left(x_{i}\right)=u_{i}^{\prime}\left(x_{i}\right) E / \xi$. In general, the markups can either increase or decrease in the consumption of each good depending on whether $\epsilon_{i}(x)$ is increasing or decreasing.

Asymmetries of preferences and costs complicate the derivation of the equilibrium because the quantity of each good depends on the quantities of all the other goods through the demand system. ${ }^{27}$ Nevertheless, combined with the demand system, the pricing conditions can be used to solve for the production rules $\underline{x}_{i}\left(c_{i}, \xi\right)$ and the budget shares $\underline{b}_{i}\left(c_{i}, \xi\right)=s_{i}\left(\underline{x}_{i}\left(c_{i}, \xi\right), \xi\right) \underline{x}_{i}\left(c_{i}, \xi\right)$ in function of the common aggregator. Using the adding up constraint $\sum_{j} \underline{b}_{j}\left(c_{j}, \xi\right)=1$ eventually one can solve for the equilibrium values of $\widehat{\xi}(\mathbf{c}, E)$, as well as for all equilibrium quantities $\widehat{x}_{i}=\underline{x}_{i}\left(c_{i}, \widehat{\xi}(\mathbf{c}, E)\right)$ and prices $\widehat{p}_{i}=s_{i}\left(\widehat{x}_{i}, \widehat{\xi}(\mathbf{c}, E)\right) E$. As we will show next, in a few examples where the subutilities have a common functional form the equilibrium values can be also derived in closed-form solutions.

Power sub-utility The simplest asymmetric case of direct additivity is based on the sub-utility power function:

$$
u_{i}(x)=\frac{\widetilde{q}_{i} x^{1-\epsilon_{i}}}{1-\epsilon_{i}}
$$

where $\epsilon_{i} \in[0,1)$ is the MEC parameter, and the demand shift parameters $\widetilde{q}_{i}>0$ could be interpreted as a quality index which can differ among goods. These preferences are a special instance of the "direct addilog" preferences presented

\footnotetext{
${ }^{25}$ For a further analysis of symmetric, additive preferences with heterogeneous firms see Zhelobodko et al. (2012) and Bertoletti and Epifani (2014).

${ }^{26}$ The second-order condition requires $x u_{i}^{\prime}(x)$ to be concave in $x$.

${ }^{27}$ In the symmetric setting of Dixit and Stiglitz (1977) the budget constraint allows the direct computation of the equilibrium price and quantity from $p=E / x n=c /(1-\epsilon(x))$.
} 
by Houthakker (1960), and also of the so-called "Constant Ratios of Elasticities of Substitution" (CRES) model of Hanoch (1975). As a straightforward non-homothetic generalization of the CES case they have been often used in applications with perfect competition. ${ }^{28}$ Since in this special case the MECs are constant, the monopolistic competition equilibrium price is:

$$
\widehat{p}_{i}=\frac{c_{i}}{1-\epsilon_{i}},
$$

which shows a full pass-through of changes in the marginal cost and independence from the pricing behavior of competitors and income. Instead the equilibrium quantities $\widehat{x}_{i}$ depend on the equilibrium value $\widehat{\xi}$, and explicit solutions are not available. Possibly due to this lack of full tractability, recent applications with quality differences (Baldwin and Harrigan, 2011, Crozet, Head and Mayer, 2012) have retained the CES structure (essentially constraining $\epsilon_{i}=\epsilon$ for any good $i$ ), which allows for differences in the demand shift parameters, but precludes any difference of markups across goods.

Stone-Geary sub-utility Consider the following simple version of the wellknown Stone-Geary preferences (see Geary, 1950-51 and Stone, 1954):

$$
u_{i}(x)=\log \left(x_{i}+\bar{x}_{i}\right),
$$

with every $\bar{x}_{i}$ positive but small enough to insure a positive demand. ${ }^{29}$ Solving for the elasticity of the perceived inverse demand we get $\epsilon_{i}(x)=x /\left(x+\bar{x}_{i}\right)$, and then the pricing condition:

$$
p_{i}\left(x_{i}\right)=c_{i}\left(1+\frac{x_{i}}{\bar{x}_{i}}\right) .
$$

The right-hand side is decreasing in $\bar{x}_{i}$ because a higher value of it increases demand elasticity. However, the equilibrium price of each firm cannot be derived independently from the behavior of competitors: the interdependence between firms created by demand conditions requires the following, fully-fledged equilibrium analysis.

By the Hotelling-Wold identity we have:

$$
s_{i}\left(x_{i}, \xi\right)=\frac{1}{\left(x_{i}+\bar{x}_{i}\right) \xi}
$$

where $\xi=\sum_{j} x_{j} /\left(x_{j}+\bar{x}_{j}\right)$. Thus we can compute the quantity $x_{i}=\sqrt{\bar{x}_{i} E /\left(c_{i} \xi\right)}-$ $\bar{x}_{i}$ and the (normalized) price rules $s_{i}=\sqrt{c_{i} /\left(\bar{x}_{i} E \xi\right)}$ for firm $i$. Define $\Psi=$

\footnotetext{
${ }^{28}$ Mukerji (1963) and Dhrymes and Kurz (1964) are early examples of these functional forms as production technologies. More recently, Fieler (2011) has used them as utility functions in a trade model.

${ }^{29}$ Simonovska (2015) has recently used a symmetric version of these preferences to study monopolistic competition among heterogeneous firms.
} 
$\sum_{j=1}^{n} \sqrt{x_{j} c_{j}}$. Using the adding up constraint we obtain the condition $n / \xi-$ $(\sqrt{E \xi})^{-1} \Psi=1$, which can be solved for the equilibrium value:

$$
\widehat{\xi}=\frac{\left[\sqrt{\Psi^{2}+4 n E}-\Psi\right]^{2}}{4 E} .
$$

Replacing $\widehat{\xi}$ in the price rule we get the final closed-form solution for the monopolistic competition price of firm $i$ :

$$
\widehat{p}_{i}=\frac{2 E \sqrt{\frac{c_{i}}{\bar{x}_{i}}}}{\sqrt{\Psi^{2}+4 n E}-\Psi} .
$$

In this example the price of each firm $i$ is increasing less than proportionally in its marginal cost $c_{i}$ (incomplete pass-through) and decreasing in the preference parameter $\bar{x}_{i}$. Moreover, an increase in income increases the price of each good less than proportionally (pricing to market). Note that each price is increasing in $\Psi$, therefore an increase in the marginal cost $c_{j}$ of a competitor or of her preference parameters $\bar{x}_{j}$ (which reduces the associated marginal utility) induce, albeit indirectly, an increase in the price of firm $i$. Finally, entry of new firms tends to reduce all prices. ${ }^{30}$

Quadratic sub-utility Consider quadratic sub-utilities as in:

$$
u_{i}(x)=\alpha_{j} x-\frac{\gamma_{j}}{2} x^{2},
$$

with $\alpha_{j}, \gamma_{j}>0$. This kind of preferences are a special instance of the quasihomothetic preferences studied by Pollak (1971), and have a long tradition in economic analysis which dates back to the work of Hermann Heinrich Gossen. Assuming that $s_{i}>0$ for all $i,{ }^{31}$ the perceived inverse demand elasticity is given by $\epsilon_{i}(x)=\gamma_{i} x /\left(\alpha_{i}-\gamma_{i} x\right)$, so that the monopolistic competition pricing condition can be computed as follows:

$$
p_{i}\left(x_{i}\right)=c_{i} \frac{\alpha_{i}-\gamma_{i} x_{i}}{\alpha_{i}-2 \gamma_{i} x_{i}} .
$$

Since $s_{i}\left(x_{i}, \xi\right)=\left(\alpha_{i}-\gamma_{i} x_{i}\right) / \xi$ we obtain the production and pricing rules $x_{i}=\left(\alpha_{i}-c_{i} \xi / E\right) / 2 \gamma_{i}$ and $s_{i}=\left(\alpha_{i}+c_{i} \xi / E\right) / 2 \xi$. Using the adding up constraint allows us to solve for the equilibrium value of the quantity aggregator as:

$$
\widehat{\xi}=2 \frac{\sqrt{\frac{\Gamma \Phi}{4 E^{2}}+1}-1}{\Gamma},
$$

\footnotetext{
${ }^{30}$ In the case of full symmetry we obtain $\widehat{p}=2 E /\left[n \bar{x}\left(\sqrt{1+\frac{4 E}{n \bar{x} c}}-1\right)\right]$, which is decresing in the number of firms $n$.

${ }^{31}$ This requires $\alpha_{i}>2 \gamma_{i} x_{i}$.
} 
where $\Gamma=\sum_{j=1}^{n} \frac{c_{j}^{2}}{\gamma_{j}}$ and $\Phi=\sum_{j=1}^{n} \frac{\alpha_{j}^{2}}{\gamma_{j}}$, and eventually to obtain the equilibrium price:

$$
\widehat{p}_{i}=\frac{c_{i}}{2}+\frac{\alpha_{i} \Gamma}{4\left(\sqrt{E^{2}+\frac{\Gamma \Phi}{4}}-E\right)} .
$$

The price of each firm $i$ is increasing less than proportionally in its marginal $\operatorname{cost} c_{i}$ as well as in the intensity of preferences for the good $\alpha_{i}$ and in income $E$, but it is also increasing in the marginal costs of competitors and decreasing in the intensity of preferences for the goods of the latter. ${ }^{32}$

\subsection{Indirectly additive preferences}

Preferences are indirectly additive when they can be represented by the indirect utility function:

$$
V=\sum_{j=1}^{n} v_{j}\left(s_{j}\right),
$$

with sub-utilities $v_{j}$ decreasing and convex (Houthakker, 1960). The symmetric version of these preferences $\left(v_{j}(s)=v(s)\right.$ for any $j$ ) has been used for the analysis of monopolistic competition in Bertoletti and Etro (2017). The direct demand system is given by:

$$
x_{i}\left(s_{i}, \rho(\mathbf{s})\right)=\frac{v_{i}^{\prime}\left(s_{i}\right)}{\rho(\mathbf{s})},
$$

with $\rho=\mu=\sum_{j=1}^{n} s_{j} v_{j}^{\prime}$ and $s_{i}\left(x_{i}, \xi\right)=v_{i}^{\prime-1}\left(x_{i} \rho\right)$, which confirms that they belong to the GAS type. Here we can express the profits of firm $i$ as:

$$
\pi_{i}=\frac{\left(s_{i} E-c_{i}\right) v_{i}^{\prime}\left(s_{i}\right)}{\rho} .
$$

For a given value of the price aggregator $\rho$ the elasticity of perceived demand $x_{i}\left(s_{i}, \rho\right)$ is given by $\varepsilon_{i}(s)=-s v_{i}^{\prime \prime}(s) / v_{i}^{\prime}(s)$, which is also the MES $\varepsilon_{i j}$ between goods $i$ and $j(i \neq j)$ and thus coincides with the average MES $\bar{\varepsilon}_{i}$ (see Section 1). The monopolistic competition price for each firm is then given by the solution to the price condition:

$$
p_{i}=\frac{\varepsilon_{i}\left(p_{i} / E\right) c_{i}}{\varepsilon_{i}\left(p_{i} / E\right)-1}, \quad i=1,2, \ldots, n .
$$

Remarkably, each condition (41) is now sufficient to determine the monopolistic competition price of each firm in function of its own marginal cost and income. Under weak conditions one can also insure existence and uniqueness of the equilibrium (see Bertoletti and Etro, 2017). This means that for the

\footnotetext{
${ }^{32}$ Under full symmetry we have $\widehat{p}=\frac{c}{2}\left\{1+\alpha n c /\left[\sqrt{(2 \gamma E)^{2}+(\alpha c n)^{2}}-\gamma E\right]\right\}$, which can be shown to be decreasing in the number of firms.
} 
entire class of indirectly additive preferences each firm $i$ can choose its price $\widehat{p}_{i}\left(c_{i}, E\right)$ under monopolistic competition independently from the behavior and the number of the competitors, as well as from their cost conditions or from parameters concerning their goods (e.g., from their "qualities"). ${ }^{33}$ All the equilibrium quantities (and the other firm-level variables, such as sales and profits) as well as welfare can then be recovered from the direct demand functions. This family of preferences could be naturally employed in multicountry trade models, whereas the effects of differential trade costs, qualities and demand elasticities could be empirically assessed. A natural outcome of these models is that goods of higher quality and/or lower substitutability will generate higher revenues in a given market and therefore will be more likely to be exported to more distant countries. Such Alchian-Allen effects (of "shipping the good apples out") have been explored in recent works by Baldwin and Harrigan (2011), Crozet, Head and Mayer (2012), Feenstra and Romalis (2014) and others, but always retaining the CES structure that generates identical markups across goods. The indirectly additive specification allows one to move easily beyond the case of common markups, as we will see in few examples.

Power sub-utility Consider a power sub-utility as:

$$
v_{i}(s)=\frac{q_{i} s^{1-\varepsilon_{i}}}{\varepsilon_{i}-1},
$$

where heterogeneity derives from both the shift parameter $q_{i}>0$ and the constant MES parameter $\varepsilon_{i}>1$, implying that preferences are neither CES nor homothetic (unless $\varepsilon_{j}=\varepsilon$ for any $j$ ). This generalization of the CES case is a special instance of the "indirect addilog" preferences of Houthakker (1960), and also of the so-called "Constant Differences of Elasticities of Substitution" (CDE) model (Hanoch, 1975). The pricing of firm $i$ under monopolistic competition is immediately derived as:

$$
\widehat{p}_{i}=\frac{\varepsilon_{i} c_{i}}{\varepsilon_{i}-1},
$$

which implies again full pass-through of changes of the marginal cost. It is straightforward to derive the equilibrium quantity:

$$
\widehat{x}_{i}=\frac{q_{i}\left[\frac{\left(\varepsilon_{i}-1\right) E}{c_{i} \varepsilon_{i}}\right]^{\varepsilon_{i}}}{\sum_{j=1}^{n} q_{j}\left[\frac{\left(\varepsilon_{j}-1\right) E}{\varepsilon_{j} c_{j}}\right]^{\varepsilon_{j}-1}},
$$

and consequently sales and profits. Clearly, $q_{i}$ is a shift parameter capturing the quality of good $i$, that leaves unchanged the price but increases profit by increasing sales. The relative production, sales and profits of firms depend on the relative quality of their goods, on their cost efficiency and demand elasticity,

\footnotetext{
${ }^{33}$ Moreover, entry of new firms, due for instance to a widening of the market size, does not affect the prices of the existing firms, but just creates welfare gains from variety for the consumers.
} 
and on the level of income in simple ways that can be exploited in empirical work. We can also solve for equilibrium welfare as:

$$
\widehat{V}=\sum_{j=1}^{n} \frac{q_{j}\left(\varepsilon_{j} c_{j}\right)^{1-\varepsilon_{j}} E^{\varepsilon_{j}-1}}{\left(\varepsilon_{j}-1\right)^{2-\varepsilon_{j}}},
$$

which allows one to compute easily the welfare impact of any parameter change.

Translated power sub-utility Consider the following sub-utility:

$$
v_{i}(s)=\frac{\left(a_{i}-s\right)^{1+\gamma_{i}}}{1+\gamma_{i}},
$$

with $a_{i}, \gamma_{i}>0$ (and $v_{i}(s)=0$ if $s>a_{i}$ ). It delivers simple perceived demand functions, including the cases of linear, perfectly rigid and perfectly elastic demands, depending on the specific value of the parameter $\gamma_{i}$. The symmetric version has been recently applied in Bertoletti et al. (2018) to study the welfare impact of trade liberalization in a multicountry trade model with heterogeneous firms. Since $\varepsilon_{i}(s)=\gamma_{i} s_{i} /\left(a_{i}-s_{i}\right)$, the price of firm $i$ is then:

$$
\widehat{p}_{i}=\frac{a_{i} E+\gamma_{i} c_{i}}{1+\gamma_{i}},
$$

which shows incomplete pass-through of marginal cost changes (parametrized by the firm-specific parameter $\gamma_{i}$ ) and markups increasing in the intensity of preference for each good (as captured by parameter $a_{i}$ ) and in income.

Exponential sub-utility Consider the case of the exponential preferences:

$$
v_{i}(s)=q_{i} e^{-\chi_{i} s},
$$

with $q_{i}, \chi_{i}>0$. These preferences deliver loglinear demand functions with variable semi-elasticities given by the paremeters $\chi_{i}$. Since $\varepsilon_{i}(s)=\chi_{i} s$ the monopolistic competition equilibrium price is:

$$
\widehat{p}_{i}=c_{i}+\frac{E}{\chi_{i}} .
$$

Summarizing, these examples provide closed-form solutions for equilibrium prices, quantities and welfare. What is important to remark, is that indirect additivity separates price decisions between firms under monopolistic competition, therefore we could obtain the equilibrium values even if the subutilities had different functional forms across goods. However, pricing does depend on the characteristics of the market, being in general affected by the willingness to pay for the product (which depends on its substitutability and on the expenditure level) and by the cost to serve it. This flexibility, together with the unique property of generating demand functions that can be described empirically by a standard multinomial logit model (see Thisse and Ushchev, 2016), make this class of preferences particularly useful for developing and estimating models with heterogeneous goods. 


\subsection{Gorman-Pollak preferences}

Building on Gorman (1970a) and Pollak (1972), ${ }^{34}$ Gorman (1987) has characterized the other main class of GAS preferences by the following extension of additivity. Suppose that preferences can be represented by the utility functions:

$$
\underline{U}(\mathbf{x}, \xi)=\sum_{j=1}^{n} u_{j}\left(\xi x_{j}\right)-\phi(\xi) \quad \text { and } \quad \underline{V}(\mathbf{s}, \rho)=\sum_{j=1}^{n} v_{j}\left(\rho s_{j}\right)-\theta(\rho),
$$

where $\xi$ can be seen as a choice variable generating the benefit of increasing the effective quantity of good $i$ to $\xi x_{i}$ at the utility cost $\phi(\xi)$, which is equivalent (in the dual representation of preferences) to the possibility of reducing the inconvenience of consumption $\theta(\rho)$ at the cost of increasing the effective price of good $i$ to $\rho s_{i}$. Intuitively, one can think of the auxiliary choice variables as related to shopping: spending more time in shopping is costly but increases the quality of each consumed variety or allows one to find the same quality at a lower price.

We label these as "Gorman-Pollak" preferences: as far as we know, they have never been used. Retaining our previous assumptions on sub-utilities, the interior optimal values $\xi(\mathbf{x})$ and $\rho(\mathbf{s})$ must satisfy the implicit first-order conditions:

$$
\phi^{\prime}(\xi)=\sum_{j=1}^{n} u_{j}^{\prime}\left(\xi x_{j}\right) x_{j} \quad \text { and } \quad \theta^{\prime}(\rho)=\sum_{j=1}^{n} v_{j}^{\prime}\left(\rho s_{j}\right) s_{j} .
$$

The demand system can then be easily computed as:

$$
s_{i}(\mathbf{x})=\frac{u_{i}^{\prime}\left(\xi(\mathbf{x}) x_{i}\right)}{\phi^{\prime}(\xi(\mathbf{x}))} \quad \text { and } \quad x_{i}(\mathbf{s})=\frac{v_{i}^{\prime}\left(\rho(\mathbf{s}) s_{i}\right)}{\theta^{\prime}(\rho(\mathbf{s}))}
$$

which show that the Gorman-Pollak preferences belong to the GAS type of preferences, and are homothetic if the additive term $\sum_{j} u_{j}$ belongs to the socalled "Bergson family" (see Burk, 1936). It can be shown that $\rho=\phi^{\prime}(\xi)$ and $\xi=-\theta^{\prime}(\rho)$, so that the optimal choices satisfy also:

$$
\rho(\mathbf{s}) s_{i}=u_{i}^{\prime}\left(\xi(\mathbf{x}) x_{i}\right) \quad \text { and } \quad \xi(\mathbf{x}) x_{i}=-v_{i}^{\prime}\left(\rho(\mathbf{s}) s_{i}\right),
$$

and $\widetilde{\mu}=\rho \xi$. Alternatively, preferences which belong to the Gorman-Pollak class can be directly represented by:

$$
U(\mathbf{x})=\sum_{j} u_{j}\left(\xi(\mathbf{x}) x_{j}\right)-\phi(\xi(\mathbf{x})) \quad \text { and } \quad V(\mathbf{s})=\sum_{j} v_{j}\left(\rho(\mathbf{s}) s_{j}\right)-\theta(\rho(\mathbf{s})),
$$

where the aggregators $\xi(\mathbf{x})$ and $\rho(\mathbf{s})$ are defined in (49).

To obtain a monopolistic competition equilibrium, let us define the elasticities:

$$
\epsilon_{i}(z) \equiv-\frac{u_{i}^{\prime \prime}(z) z}{u_{i}^{\prime}(z)} \quad \text { and } \quad \varepsilon_{i}(z) \equiv-\frac{v_{i}^{\prime \prime}(z) z}{v_{i}^{\prime}(z)} .
$$

\footnotetext{
${ }^{34}$ See Terence Gorman's collected works published in Blackorby and Shorrocks (1995).
} 
When firms maximize their profits:

$$
\pi_{i}=\left[\frac{u_{i}^{\prime}\left(\xi x_{i}\right) E}{\phi^{\prime}(\xi)}-c_{i}\right] x_{i}=\frac{\left(s_{i} E-c_{i}\right) v_{i}^{\prime}\left(\rho s_{i}\right)}{\theta^{\prime}(\rho)}
$$

taking as given the aggregators it is immediate to verify that the perceived demand elasticities of monopolistic competition are given by $\epsilon_{i}\left(\xi x_{i}\right)$ and $\varepsilon_{i}\left(\rho s_{i}\right)$, which imply the equilibrium pricing condition:

$$
p_{i}=\frac{c_{i}}{1-\epsilon_{i}\left(\xi(\mathbf{x}) x_{i}\right)}=\frac{\varepsilon_{i}\left(\rho(\mathbf{s}) s_{i}\right) c_{i}}{\varepsilon_{i}\left(\rho(\mathbf{s}) s_{i}\right)-1} .
$$

In contrast to the case of additive preferences, within the Gorman-Pollak class the relevant demand elasticities $d o$ depend in general on the values of the aggregators, and do not directly correspond to the Morishima measures. Nevertheless our result for the GAS preferences applies and the equilibrium (51) approximates the imperfect competition equilibria in which firms correctly perceive market shares when these are negligible. Moreover, while they may appear complex, the Gorman-Pollak preferences retain a tractability that is well illustrated by next example.

Self-dual addilog preferences The family of "self-dual addilog" 35 preferences introduced by Houthakker (1965) and investigated by Pollak (1972) belongs to the Gorman-Pollak class. For this family of preferences the direct demand system is given by:

$$
x_{i}(\mathbf{s})=\frac{q_{i}\left[s_{i} \rho(\mathbf{s})\right]^{-\varepsilon_{i}}}{\rho(\mathbf{s})^{\frac{\delta-1}{\delta}}},
$$

where $q_{i}>0$ is a shift parameter reflecting the quality of good $i, \varepsilon_{i}>1$ governs the perceived elasticity of demand and $\rho(\mathbf{s})$ is implicitly defined by the condition $\sum_{i=1}^{n} q_{i} s_{i}^{1-\varepsilon_{i}} \rho^{\frac{1-\delta}{\delta}-\varepsilon_{i}}=1$. We assume $\delta \in(0,1)$, and $\varepsilon_{i} \neq \varepsilon_{j}$ for some $i$ and $j$ (otherwise preferences are CES). Moreover, the inverse demand system is given by:

$$
s_{i}(\mathbf{x})=\frac{\widetilde{q}_{i}\left[x_{i} \xi(\mathbf{x})\right]^{-\epsilon_{i}}}{\xi(\mathbf{x})^{\frac{\tilde{\delta}-1}{\delta}}},
$$

where $\xi(\mathbf{x})$ is implicitly defined by the condition $\sum_{i=1}^{n} \widetilde{q}_{i} x_{i}^{1-\epsilon_{i}} \xi^{\frac{1-\widetilde{\delta}}{\delta}-\epsilon_{i}}=1$, with:

$$
\varepsilon_{i}=\frac{1}{\epsilon_{i}}>0, q_{i}=\widetilde{q}_{i}^{\epsilon_{i}} \text { and } \delta=1-\widetilde{\delta} .
$$

Pollak (1972) showed that the underlying preferences can be represented for $\delta \neq 1 / 2$ by:

$\underline{U}(\mathbf{x}, \xi)=\sum_{j=1}^{n} \frac{\widetilde{q}_{j}\left(x_{j} \xi\right)^{1-\epsilon_{j}}}{1-\epsilon_{j}}-\frac{\widetilde{\delta} \xi^{\frac{2 \widetilde{\delta}-1}{\delta}}}{2 \widetilde{\delta}-1}$ and $\underline{V}(\mathbf{s}, \rho)=\sum_{j=1}^{n} \frac{q_{j}\left(s_{j} \rho\right)^{1-\varepsilon_{j}}}{\varepsilon_{j}-1}+\frac{\delta \rho^{\frac{2 \delta-1}{\delta}}}{2 \delta-1}$.

\footnotetext{
${ }^{35}$ According to a terminology suggested by Pollak (1972), "strongly self-dual" preferences are such that they can be represented both by $U(\mathbf{x})$ and by $-U(\mathbf{s})$ : see Samuelson (1965) and Houthakker (1965).
} 
In the special case with $\delta=1 / 2=\widetilde{\delta}$ preferences are given by:

$$
\underline{U}(\mathbf{x}, \xi)=\sum_{j} \frac{\widetilde{q}_{j}\left(x_{j} \xi\right)^{1-\epsilon_{j}}}{1-\epsilon_{j}}-\ln \xi \quad \text { and } \quad \underline{V}(\mathbf{s}, \rho)=\sum_{j} \frac{q_{j}\left(s_{j} \rho\right)^{1-\varepsilon_{j}}}{\varepsilon_{j}-1}+\ln \rho,
$$

and the corresponding functions $U(\mathbf{x})$ and $V(\mathbf{s})$ are homothetic. One can indeed verify that these utility functions generate the demand systems expressed above.

Given the inverse and direct demand systems, when firms maximize profits taking as given the aggregators, we immediately obtain the following prices under monopolistic competition:

$$
\widehat{p}_{i}=\frac{c_{i}}{1-\epsilon_{i}}=\frac{\varepsilon_{i} c_{i}}{\varepsilon_{i}-1},
$$

where the idiosyncratic markups are constant as in our additive, power subutility examples. ${ }^{36}$ In fact, we can also derive the equilibrium quantities:

$$
\widehat{x}_{i}=\frac{q_{i}\left(\varepsilon_{i}-1\right)^{\varepsilon_{i}} E^{\varepsilon_{i}}}{c_{i}^{\varepsilon_{i}} \varepsilon_{i}^{\varepsilon_{i}} \rho(\widehat{\mathbf{s}})^{\frac{\delta-1}{\delta}+\varepsilon_{i}}} .
$$

These results make this family the natural extension of the power additive preferences. The availability of a homothetic version (for $\delta=1 / 2$ ), with the associated well-defined price and consumption indexes, and the flexibility of the general specification provide interesting advantages for applications departing from the CES paradigm. ${ }^{37}$

\section{Monopolistic competition with multiple ag- gregators}

In this section we extend the approach to monopolistic competition of the previous section to other types of separable preferences generating demands that depend on common aggregators. In particular, we start with the case where each demand depends on two common aggregators, and then can be written as:

$$
s_{i}=s_{i}\left(x_{i}, \xi(\mathbf{x}), \psi(\mathbf{x})\right) \quad \text { and } \quad x_{i}=x_{i}\left(s_{i}, \rho(\mathbf{s}), \omega(\mathbf{s})\right) .
$$

Assuming $\partial s_{i} / \partial x_{i}, \partial x_{i} / \partial p_{i}<0$, again we get that $s_{i}=x_{i}^{-1}\left(x_{i}, \xi(\mathbf{x}), \psi(\mathbf{x})\right)$ where $\xi(\mathbf{x})=\rho(\mathbf{s}(\mathbf{x}))$ and $\psi(\mathbf{x})=\omega(\mathbf{s}(\mathbf{x}))$. We can then keep defining unambiguously monopolistic competition as the environment in which firms adopt their strategies anticipating the correct value of aggregators but taking them as given.

\footnotetext{
${ }^{36}$ One can verify that when $\delta=1$ (52) coincides with the direct demand obtained from indirect additivity and a power sub-utility, while when $\delta=0$ (53) coincides with the inverse demand delivered from direct additivity and a power sub-utility.

${ }^{37}$ Another advantage of the self-dual addilog preferences is that they weaken the strict relationship which exists between price and income elasticities under additivity.
} 
Property (55) holds for preferences for which the marginal utility of each good can be written in a separable fashion. Suppose in particular that for any $i=1, . ., n$ we have:

$$
U_{i}(\mathbf{x})=f_{i}\left(x_{i}, \xi(\mathbf{x})\right),
$$

with $\partial f_{i} / \partial x_{i}<0$. Then, the inverse demand is:

$$
s_{i}\left(x_{i}, \xi(\mathbf{x}), \psi(\mathbf{x})\right)=\frac{f_{i}\left(x_{i}, \xi(\mathbf{x})\right)}{\psi(\mathbf{x})},
$$

where $\psi=\widetilde{\mu}=\sum_{j} x_{j} f_{j}{ }^{38}$ An example is provided by the following generalization of the Gorman-Pollak preferences:

$$
\underline{U}(\mathbf{x}, \xi)=\sum_{i} u_{i}\left(x_{i}, \xi\right)-\phi(\xi),
$$

where $\xi$ is defined by the optimality condition $\phi^{\prime}(\xi)=\sum_{j=1}^{n} x_{j} \partial u_{i}\left(x_{i}, \xi\right) / \partial \xi$, leading to $f_{i}\left(x_{i}, \xi(\mathbf{x})\right)=\partial u_{i}\left(x_{i}, \xi(\mathbf{x})\right) / \partial x_{i}$.

Other classes of preferences with demand functions depending on two aggregators can be obtained if we assume separability of the marginal indirect utility. ${ }^{39}$ In what follows we will focus our attention on two classes of preferences that generalize well-known symmetric specifications used in the theory of monopolistic competition.

\subsection{Augmented additive preferences}

Let us consider the class of preferences with direct utility:

$$
U(\mathbf{x})=\sum_{j=1}^{n} u_{j}\left(x_{j}\right)-\frac{\eta}{2} \xi(\mathbf{x})^{2},
$$

where $\eta>0$ and $\xi(\mathbf{x})=\sum_{j=1}^{n} x_{j}$. One can recognize here the non-linear component of the utility specification used by Melitz and Ottaviano (2008) with a common and quadratic subutility $u_{j}(x)=\alpha x-\frac{\gamma}{2} x^{2}$ for any $j$. This class of preferences satisfies the separability (56) with $f_{i}\left(x_{i}, \xi(\mathbf{x})\right)=u_{i}^{\prime}\left(x_{i}\right)-$ $\eta \xi(\mathbf{x})$. Within this class we have market shares $b_{i}=\left(u_{i}^{\prime}-\eta \xi\right) x_{i} / \psi$, and the corresponding perceived elasticity of inverse demand is given by:

$$
\epsilon_{i}\left(x_{i}, \xi\right)=\frac{-u_{i}^{\prime \prime}\left(x_{i}\right) x_{i}}{u_{i}^{\prime}\left(x_{i}\right)-\eta \xi}
$$

which allows one to compute the pricing conditions.

It is useful to consider an example of this class of preferences to sketch how in principle one can apply the solution procedure of Section 2 in the presence

\footnotetext{
${ }^{38}$ An example of this demand structure with symmetric preferences is considered by Arkolakis et al. (2015).

${ }^{39}$ See the case of the generalized quadratic preferences presented in Bertoletti and Etro (2016) in a symmetric version.
} 
of two aggregators. Consider the quadratic subutility $u_{j}(x)=\alpha_{j} x-\frac{\gamma_{j}}{2} x^{2}$. The pricing condition becomes:

$$
p_{i}\left(x_{i}\right)=c_{i}\left(\frac{\alpha_{i}-\gamma_{i} x_{i}-\eta \xi}{\alpha_{i}-2 \gamma_{i} x_{i}-\eta \xi}\right),
$$

and by the Hotelling-Wold identity we have:

$$
s_{i}\left(x_{i}, \xi, \psi\right)=\frac{\alpha_{i}-\gamma_{i} x_{i}-\eta \xi}{\psi},
$$

where $\psi=\sum_{j} x_{j}\left(\alpha_{j}-\gamma_{j} x_{j}-\eta \xi\right)$. Thus we can compute the quantity rules $x_{i}=\left(\alpha_{i}-\eta \xi-\psi c_{i} / E\right) / 2 \gamma_{i}$ and the pricing rules $s_{i}=\left(\alpha_{i}-\eta \xi+c_{i} \psi / E\right) / 2 \psi$. Using the budget constraint one can solve for the marginal utility of income $\psi(\xi)$ in function of the other aggregator and for the quantity $x_{i}(\xi, \psi(\xi))$. Using the definition $\xi=\sum_{j=1}^{n} x_{j}(\xi, \psi(\xi))$ eventually we solve for $\widehat{\xi}(\mathbf{c}, E)$ and $\psi(\widehat{\xi}(\mathbf{c}, E))$ and derive the prices:

$$
\hat{p}_{i}=\frac{c_{i}}{2}+\frac{\left(\alpha_{i}-\eta \widehat{\xi}(\mathbf{c}, E)\right) E}{2 \psi(\widehat{\xi}(\mathbf{c}, E))},
$$

which generalize (38). ${ }^{40}$

\subsection{Implicitly additive preferences}

Another interesting class of demands satisfying (55) is delivered by Hanoch's (1975) implicit additivity, which has been exploited by Kimball (1995) for the analysis of homothetic (symmetric) technologies under monopolistic competition, and more recently by Feenstra and Romalis (2014) to study endogenous qualities, ${ }^{41}$ and by Matsuyama (2017) to analyze the impact of nonhomotheticity on structural change. Here we discuss the class of preferences

\footnotetext{
${ }^{40}$ One can also consider an asymmetric version of the quasilinear preferences used originally by Melitz and Ottaviano (2008):

$$
U=x_{0}+\sum_{j=1}^{n} \alpha_{j} x_{j}-\frac{1}{2} \sum_{j=1}^{n} \gamma_{j} x_{j}^{2}-\frac{\eta}{2} \xi^{2},
$$

with $\alpha_{j}, \gamma_{j}, \eta>0$ and $\xi=\sum_{j} x_{j}$. If the outside good 0 is the numeraire we have the linear inverse demands $p_{i}=\alpha_{i}-\gamma_{i} x_{i}-\eta \xi$ which exhibit the GAS property. It is immediate to express the profit (per consumer) of each firms as $\pi_{i}=\left[\alpha_{i}-\gamma_{i} x_{i}-\eta \xi-c_{i}\right] x_{i}$. Taking $\xi$ as given, profits are maximized producing $x_{i}=\left(\alpha_{i}-\eta \xi-c_{i}\right) / 2 \gamma_{i}$, which allows one to compute $\widehat{\xi}$ and then the equilibrium price as:

$$
\widehat{p}_{i}=\frac{c_{i}+\alpha_{i}}{2}-\frac{\frac{\eta}{2} \sum_{j=1}^{n} \frac{\alpha_{j}-c_{j}}{\gamma_{j}}}{2+\eta \sum_{j=1}^{n} \gamma_{j}^{-1}} .
$$

Notice that one could easily solve also for the asymmetric Cournot equilibrium, where firms do not take $\xi$ as given.

${ }^{41}$ Feenstra and Romalis (2014) actually use an expenditure function with an "implicitly additive" functional form. However, by a result of Blackorby et al. (1978: Theorem 4.10, p. 149) this is equivalent to direct implicit additivity of preferences under some regularity conditions.
} 
that are directly implicitly additive and not necessarily homothetic; similar results apply when preferences are indirectly implicitly additive.

Let us assume that preferences can be represented by a utility $U(\mathbf{x})$ which is implicitly defined by:

$$
F(\mathbf{x}, U)=\sum_{j=1}^{n} F^{j}\left(x_{j}, U\right) \equiv 1,
$$

where the "transformation function" $F$ satisfies the relevant regularity conditions ( $F$ must be monotonic). Then preferences are (directly) implicitly additive (notice that additivity is a special case of implicit additivity). These preferences are homothetic if $F^{j}\left(x_{j}, U\right)=F^{j}\left(x_{j} / U\right)$ for any $j$, which is the case considered by the literature following Kimball (1995). The marginal utility of commodity $i$ is given by:

$$
U_{i}(\mathbf{x})=\frac{-F_{i}^{i}\left(x_{i}, U\right)}{\sum_{j=1}^{n} F_{U}^{j}\left(x_{j}, U\right)} .
$$

The FOCs for utility maximization imply $-F_{i}^{i} /\left[\sum_{j} F_{U}^{j}\right]=\widetilde{\mu} s_{i}$, and the inverse demand system is given by:

$$
s_{i}(\mathbf{x})=\frac{F_{i}^{i}\left(x_{i}, \xi(\mathbf{x})\right)}{\psi(\mathbf{x})}
$$

for $i=1, . ., n$, where $\xi=U$ and $\psi=\sum_{j} F_{j}^{j} x_{j}$. Thus, in this case one aggregator is the utility itself and the perceived inverse demand elasticity is given by the function:

$$
\epsilon_{i}\left(x_{i}, U\right)=-\frac{F_{i i}^{i}\left(x_{i}, U\right) x_{i}}{F_{i}^{i}\left(x_{i}, U\right)} .
$$

As Hanoch (1975) noted, the properties of the "substitution function" $x_{i} F_{i i}^{i} / F_{i}^{i}$ completely determine the substitutability of good $i$ along an indifference curve. ${ }^{42}$ In our monopolistic competition setting, it does also determine the perceived demand elasticity. In Appendix B we prove that also in the case of implicit additivity when the market shares become negligible the perceived demand elasticity does approximate the average Morishima measure. Accordingly the monopolistic competition equilibrium where firms take aggregators as given approximates the imperfect competition equilibria of Section 1, which in this sense do converge.

We conclude by discussing an example that, as far as we know, has never been used under monopolistic competition, but that could be useful in both trade and macroeconomic applications.

\footnotetext{
${ }^{42}$ Useful cases arise when the substitution functions are simple. Among them are CES generalizations mentioned in Section 2: the so-called CRES and CDE. However, it is worth mentioning that the elasticities of substitution to which this terminology refers are not the gross Morishima we use in this paper, but the net Allen-Uzawa measures: see Blackorby and Russell (1981).
} 
Implicit CES preferences A family of preferences of particular interest is given by the "implicit CES" preferences. They emerge with the following specification of implicit additivity (Gorman, 1970a and 1970b, and Blackorby and Russell, 1981):

$$
F^{j}\left(x_{j}, U\right)=q_{j}(U) x_{j}^{1-\epsilon(U)},
$$

with $\epsilon(U)$ and $q_{j}(U)$ that are constant for a given utility level but can change across indifference curves. Note that all $F^{j}$ are homogeneous of the same degree $1-\epsilon$ with respect to $x_{j}$ : then $x_{j} F_{j}^{j}=(1-\epsilon) F^{j}$ and $\psi=1-\epsilon$. Thus by the Hotelling-Wald identity the inverse demand of commodity $i$ is given by:

$$
s_{i}(\mathbf{x})=q_{i}(U(\mathbf{x})) x_{i}^{-\epsilon(U(\mathbf{x}))},
$$

therefore this family of preferences is actually a member of the GAS preferences. Moreover, one can prove that the preferences characterized by (63) are the only additive preferences that deliver symmetric perceived demand elasticities, namely $\epsilon_{i}=\epsilon(U)$ for all $i .{ }^{43}$ Accordingly the monopolistic competition prices satisfy:

$$
p_{i}=\frac{c_{i}}{1-\epsilon(U(\mathbf{x}))},
$$

which requires $\epsilon \in(0,1)$ and shows that markups are identical across firms in spite of the differences among goods. Nevertheless, markups possibly vary according to changes in expenditure or costs through their impact on the equilibrium utility, which makes this specification particularly attractive. ${ }^{44}$

Interesting applications of these preferences could emerge in a macroeconomic setting, departing from the homothetic specification suggested by Kimball (1995). The advantage of intratemporal preferences as the implicit CES is that they deliver markups that depend on an aggregate variable such as utility and, therefore, the level of expenditure. This implies that aggregate shocks affect the economy not only through the traditional channels, but also through their impact on markups. In particular, countercyclical markups tend to magnify

${ }^{43}$ Integrating twice

$$
-\frac{\epsilon_{i}(U)}{x_{i}}=-\frac{F_{i i}^{i}\left(x_{i}, U\right)}{F_{i}^{i}\left(x_{i}, U\right)}
$$

with respect to $x_{i}$ one gets:

$$
F^{i}\left(x_{i}, U\right)=q_{i}(U) x_{i}^{1-\epsilon(U)}+\kappa_{i}(U),
$$

where $q_{i}$ and $\kappa_{i}$ are arbitrary functions. However, sharing the same indifference curves, the preferences which can be characterized by

$$
\sum_{j}\left[q_{j}(U) x_{j}^{1-\epsilon(U)}+\kappa_{j}(U)\right] \equiv 1
$$

and those implied by (63) must be the same.

${ }^{44}$ This family of preferences includes cases where the elasticity $\epsilon$ is constant and only $q_{i}$ changes with utility, as in the "non-homothetic CES" CRES of Hanoch (1975), for which $F^{j}\left(x_{j}, U\right)=d_{i} U^{-e_{i}(1-\epsilon)} x_{i}^{1-\epsilon}$ with $d_{i}$ and $e_{i}$ positive parameters affecting both price and income demand elasticities. Preferences become homothetic when the parameters $e_{i}$ are identical. See Feenstra and Romalis (2014) and Matsuyama (2017) for other examples of similar preferences. 
the propagation of positive temporary shocks because they induce a temporary reduction in the relative price of the final goods, which boosts consumption, and a temporary increase of the real wages, which incentivizes labor supply, while the opposite happens in case of procyclical markups. ${ }^{45}$

\subsection{Several aggregators}

We conclude this part noting that in principle the approach to monopolistic competition that we have explored when preferences are separable can be extended to cases in which each demand function depends on three or more aggregators. In fact, the associated procedure to determine the equilibrium could be applied to any system of well defined "perceived" demands as soon as the alledged behavioral rules (based on the perceived demand elasticities) were consistent with the demand system, so that firms could be seen as correctly anticipating the actual demands.

\section{Conclusion}

Following our earlier investigations, we have analyzed imperfect and monopolistic competition when consumers have asymmetric preferences over many differentiated commodities and firms are heterogeneous in costs. Defining monopolistic competition as the market structure which arises when market shares are perceived as negligible, we have been able to obtain a well-defined and workable characterization of monopolistic competition pricing. Moreover, we have presented a simple and consistent approach to monopolistic competition for demand functions depending on common aggregators.

We believe that our approach could be usefully employed in trade and macroeconomic applications. Most of the recent research on heterogeneous firms is actually based on symmetric preferences (Melitz, 2003; Melitz and Ottaviano, 2008; Arkolakis et al., 2015), which is hardly realistic, especially to analyze heterogenous quality. Also the macroeconomic applications of monopolistic competition have usually focused on symmetric preference aggregators (Bilbiie et al., 2012; Etro, 2016; Boucekkine et al., 2017). Departing from these assumptions would allow to examine markup variability among goods and over time and its influence along the business cycle and across countries. Finally, the functional forms for separable preferences that we have considered await for an empirical assessment.

\footnotetext{
${ }^{45}$ A quantitative analysis of similar substitution effects is in Cavallari and Etro (2017). Their preferences generate countercyclical markups under monopolistic competition, which allows the model to outperform a standard Real Business Cycle version with perfect competition in matching moments of the aggregate variables.
} 


\section{References}

Arkolakis, Costas, Arnaud Costinot, Dave Donaldson and Andrés RodríguezClare, 2015, The Elusive Pro-Competitive Effects of Trade, WP 21370, NBER

Baldwin, Richard and James Harrigan, 2011, Zeros, quality, and space: Trade theory and trade evidence, American Economic Journal: Microeconomics, 3, $2,60-88$

Benassy, Jean Paul, 1996, Taste for Variety and Optimum Production patterns in Monopolistic Competition, Economics Letters, 52, 1, 41-7

Bertoletti, Paolo and Paolo Epifani, 2014, Monopolistic Competition: CES Redux?', Journal of International Economics, 93, 2, 227-38

Bertoletti, Paolo and Federico Etro, 2016, Preferences, Entry and Market Structure, RAND Journal of Economics, 47, 4, 792-821

Bertoletti, Paolo and Federico Etro, 2017, Monopolistic Competition when Income Matters, Economic Journal, in press

Bertoletti, Paolo, Federico Etro and Ina Simonovska, 2018, International Trade with Indirect Additivity, American Economic Journal: Microeconomics, forthcoming

Bilbiie, Florin, Fabio Ghironi and Marc Melitz, 2012, Endogenous Entry, Product Variety, and Business Cycles, Journal of Political Economy, 120, 2, 304-45

Blackorby, Charles and R. Robert Russell, 1981, The Morishima Elasticity of Substitution: Symmetry, Constancy, Separability, and its Relationship to the Hicks and Allen Elasticities, Review of Economic Studies, 48, 147-58

Blackorby, Charles and Anthony F. Shorrocks, 1995, Collected Works of W.M. Gorman: Separability and Aggregation, Oxford: Oxford University Press

Blackorby, Charles, Daniel Primont and R. Robert Russell, 1978, Duality, Separability, and Functional Structure: Theory and Economic Applications, New York: Elsevier North-Holland

Blackorby, Charles, Daniel Primont and R. Robert Russell, 2007, The Morishima Gross Elasticity of Substitution, Journal of Productivity Analysis, 28, 203-8

Blanchard, Oliver and Nobuhiro Kiyotaki, 1987, Monopolistic Competition and the Effects of Aggregate Demand, American Economic Review, 77, 4, 647-66

Boucekkine, Raouf, Hélène Latzer and Mathieu Parenti, 2017, Variable Markups in the Long-Run: A Generalization of Preferences in Growth Models, Journal of Mathematical Economics, 68C, 80-6

Burk (Bergson), Abram, 1936, Real Income, Expenditure Proportionality, and Frisch's "New Methods of Measuring Marginal Utility", Review of Economic Studies, 4, 1, 33-52

Cavallari, Lilia and Federico Etro, 2017, Demand, Markups and the Business Cycle, mimeo, University of Rome III

Chamberlin, Edward, 1933, The Theory of Monopolistic Competition: A Reorientation of the Theory of Value, Cambridge: Harvard University Press

Chamberlin, Edward, 1937, Monopolistic or Imperfect Competition?, Quarterly Journal of Economics, 51, 557-80 
Christensen, Laurits, Dale Jorgenson and Lawrence Lau, 1975, Transcendental logarithmic utility functions, The American Economic Review, 65, 3 367-383

Crozet, Matthieu, Keith Head and Thierry Mayer, 2012, Quality sorting and trade: Firm-level evidence for French wine, Review of Economic Studies, 79, $2,609-644$

d'Aspremont, Claude and Rodolphe Dos Santos Ferreira, 2016, Oligopolistic vs. monopolistic competition: Do intersectoral effects matter?, Economic Theory, 62, 1-2, 299-324

Dhrymes, Phoebus and Mordecai Kurz, 1964, Technology and Scale in Electricity Generation, Econometrica, 32, 3, 287-315

Diewert, Walter E., 1971, An Application of the Shephard Duality Theorem: A Generalized Leontief Production Function, Journal of Political Economy, 79, $3,481-507$

Dixit, Avinash and Joseph Stiglitz, 1977, Monopolistic Competition and Optimum Product Diversity, The American Economic Review, 67, 297-308

Dixit, Avinash and Joseph Stiglitz, 1993, Monopolistic Competition and Optimum Product Diversity: Reply, The American Economic Review, 83, 1, $302-4$

Etro, Federico, 2016, The Ramsey Model with Monopolistic Competition and General Preferences, Economics Letters, 145, 141-4

Etro, Federico, 2017, The Heckscher-Ohlin Model with Monopolistic Competition and General Preferences, Economics Letters, forthcoming

Feenstra, Robert, 2003, A Homothetic Utility Function for Monopolistic Competition Models without Constant Price Elasticity, Economics Letters, 78, 1, $79-86$

Feenstra, Robert, 2014, Restoring the Product Variety and Pro-Competitive Gains from Trade with Heterogeneous Firms and Bounded Productivity, NBER WP 16796

Feenstra, Robert, and John Romalis, 2014, International prices and endogenous quality, Quarterly Journal of Economics, 129, 2, 477-527

Fieler, Ana Cecilia, 2011, Non-homotheticity and Bilateral Trade: Evidence and a Quantitative Explanation, Econometrica, 79, 4, 1069-101

Geary, Roy, 1950-51, A Note on 'A Constant Utility Index of the Cost of Living', Review of Economic Studies, 18, 1, 65-6

Ghironi, Fabio and Marc Melitz, 2005, International Trade and Macroeconomic Dynamics with Heterogenous Firms, Quarterly Journal of Economics, 120, 865-915

Gorman, William Moore (Terence), 1970a, Conditions for Generalized Additive Separability, in Charles Blackorby and Anthony F. Shorrocks Eds., 1995, Vol. 1, 186-207

Gorman, William Moore (Terence), 1970b, Quasi-Separable Preferences, Costs, and Technologies, in Charles Blackorby and Anthony F. Shorrocks Eds., 1995, Vol. 1, 104-114

Gorman, William Moore (Terence), 1987, Separability, The New Palgrave: A Dictionary of Economics, 4, London: Macmillan Press, 305-11 
Hanoch, Giona, 1975, Production and Demand Models with Direct or Indirect Implicit Additivity, Econometrica, 43, 3, 395-419

Houthakker, Hendrik, 1960, Additive Preferences, Econometrica, 28, 2, 244-57

Houthakker, Hendrik, 1965, A note on self-dual preferences, Econometrica, 33, 4, 797-801

Kimball, Miles, 1995, The Quantitative Analytics of the Basic Neomonetarist Model, Journal of Money, Credit and Banking, 27, 1241-77

Krugman, Paul, 1980, Scale Economies, Product Differentiation, and the Pattern of Trade, The American Economic Review, 70, 950-9

Matsuyama, Kiminori, 2017, Engel's Law in the Global Economy: DemandInduced Patterns of Structural Change and Trade across Countries, mimeo, Northwestern University

Melitz, Marc, 2003, The Impact of Trade on Intra-Industry Reallocations and Aggregate Industry Productivity, Econometrica, 71, 6, 1695-725

Melitz, Marc and Gianmarco Ottaviano, 2008, Market Size, Trade, and Productivity, Review of Economic Studies 75, 1, 295-316

Morishima, Michio, 1967, A Few Suggestions on the Theory of Elasticity, Keizai Hyoron, 16, 144-50

Mrázová, Monika and J. Peter Neary (2017). "Selection Effects with Heterogeneous Firms," mimeo, University of Oxford

Mukerji, V., 1963, A Generalized SMAC Function with Constant ratios of Elasticity of Substitution, Review of Economic Studies, 30, 3, 233-6

Parenti, Mathieu, Philip Ushchev and Jean-Francois Thisse, 2017, Toward a Theory of Monopolistic Competition, Journal of Economic Theory, 167 (C), $86-115$

Pascoa, Mario Rui, 1997, Monopolistic Competition and Non-Neighboring-Goods, Economic Theory, 9, 129-42

Pollak, Robert, 1971, Additive utility functions and linear Engel curves, Review of Economic Studies, 38, 4, 401-14

Pollak, Robert, 1972, Generalized Separability, Econometrica, 40, 3, 431-53

Robinson, Joan, 1933, The Theory of Imperfect Competition, London: McMillan

Samuelson, Paul, 1965, Using full Duality to show that Simultaneously Additive Direct and Indirect Utilities implies Unitary Price Elasticity of Demand, Econometrica, 33, 4, 781-96

Simonovska, Ina, 2015, Income Differences and Prices of Tradables, Review of Economic Studies, 82, 4, 1612-56

Stone, Richard, 1954, Linear Expenditure Systems and Demand Analysis: An Application to the Pattern of British Demand, The Economic Journal, 64, $255,511-27$

Thisse, Jean-Francois and Philip Ushchev, 2016, When Can a Demand System Be Described by a Multinomial Logit with Income Effect?, Higher School of Economics Research Paper No. 139

Vives, Xavier, 1987, Small Income Effects: A Marshallian theory of consumer surplus and downward sloping demand, Review of Economic Studies, 54, 1, $87-103$ 
Vives, Xavier, 1999, Oligopoly Pricing. Old Ideas and New Tools, London: MIT Press

Yang, Xiaokai and Ben J. Heijdra, 1993, Monopolistic Competition and Optimum Product Diversity: Comment, The American Economic Review, 83, 1, 295-301

Woodford, Michael, 2003, Interest and Prices, Princeton University Press

Zhelobodko, Evgeny, Sergey Kokovin, Mathieu Parenti and Jacques-François Thisse, 2012, Monopolistic Competition in General Equilibrium: Beyond the CES, Econometrica, 80, 6, 2765-84

\section{Appendix}

A: Monopolistic competition with GAS preferences. Assume that preferences belonging to the GAS type. Taking as given the relevant aggregator, in a monopolistic competition equilibrium firms compute the perceived demand elasticity according to:

$$
\epsilon_{i}=-\frac{\partial \ln s_{i}\left(x_{i}, \xi\right)}{\partial \ln x_{i}}=\left[-\frac{\partial \ln x_{i}\left(s_{i}, \rho\right)}{\partial \ln s_{i}}\right]^{-1}=\varepsilon_{i}^{-1} .
$$

We now show that, when market shares are indeed negligible, to take aggregators as given is approximately optimal and approximately coincides with using the average Morishima measures as the relevant demand elasticities (cross demand effects are approximately zero unless the own demand elasticities are large).

Let us start by computing the MEC between commodities $i$ and $j(i \neq j)$ :

$$
\begin{array}{r}
\epsilon_{i j}=-\frac{\partial \ln \left\{s_{i}(\mathbf{x}) / s_{i}(\mathbf{x})\right\}}{\partial \ln x_{i}}=\frac{\partial \ln s_{j}\left(x_{j}, \xi(\mathbf{x})\right)}{\partial \ln x_{i}}-\frac{\partial \ln s_{i}\left(x_{i}, \xi(\mathbf{x})\right)}{\partial \ln x_{i}} \\
=\left[\frac{\partial \ln s_{j}\left(x_{j}, \xi(\mathbf{x})\right)}{\partial \ln \xi}-\frac{\partial \ln s_{i}\left(x_{i}, \xi(\mathbf{x})\right)}{\partial \ln \xi}\right] \frac{\partial \ln \xi(\mathbf{x})}{\partial \ln x_{i}}-\frac{\partial \ln s_{i}\left(x_{i}, \xi(\mathbf{x})\right)}{\partial \ln x_{i}} .
\end{array}
$$

This implies $(h \neq i \neq j)$

$$
\epsilon_{i j}-\epsilon_{i h}=\left[\frac{\partial \ln s_{j}\left(x_{j}, \xi(\mathbf{x})\right)}{\partial \ln \xi}-\frac{\partial \ln s_{h}\left(x_{i}, \xi(\mathbf{x})\right)}{\partial \ln \xi}\right] \frac{\partial \ln \xi(\mathbf{x})}{\partial \ln x_{i}},
$$

and:

$\bar{\epsilon}_{i}=\left[\sum_{j \neq i} \frac{\partial \ln s_{j}\left(x_{j}, \xi(\mathbf{x})\right)}{\partial \ln \xi} \frac{b_{j}(\mathbf{x})}{1-b_{i}(\mathbf{x})}-\frac{\partial \ln s_{i}\left(x_{i}, \xi(\mathbf{x})\right)}{\partial \ln \xi}\right] \frac{\partial \ln \xi(\mathbf{x})}{\partial \ln x_{i}}-\frac{\partial \ln s_{i}\left(x_{i}, \xi(\mathbf{x})\right)}{\partial \ln x_{i}}$.

By differentiating the identity $\sum_{j} s_{i}\left(x_{j}, \xi\right) x_{j}=1$ we can compute:

$$
\frac{\partial \ln \xi(\mathbf{x})}{\partial \ln x_{i}}=-\frac{\frac{\partial \ln s_{i}\left(x_{i}, \xi(\mathbf{x})\right)}{\partial \ln x_{i}}+1}{\sum_{j=1}^{n} \frac{\partial \ln s_{j}\left(x_{j}, \xi(\mathbf{x})\right)}{\partial \ln x_{j}}} \frac{b_{i}(\mathbf{x})}{\xi(\mathbf{x})^{2}} .
$$


Accordingly we have $\bar{\epsilon}_{i} \approx \epsilon_{i} \approx \epsilon_{i j}$ when $b_{i} \approx 0 .{ }^{46}$ Notice that $\bar{\epsilon}_{i}=\epsilon_{i}=\epsilon_{i j}$ even when shares are not negligible if both preferences and the consumption bundle (and then the price vector) are symmetric (as in Bertoletti and Etro, 2016). Analogously, one can derive the MES and show that with GAS preferences small market shares imply $\bar{\varepsilon}_{i} \approx \varepsilon_{i} \approx \varepsilon_{i j}$ and thus $\bar{\varepsilon}_{i} \approx \bar{\epsilon}_{i}^{-1}$.

B: Monopolistic competition with implicitly additive preferences. Let us consider first the directly implicitly additive preferences defined by (61). Since $\ln \left(s_{i} / s_{j}\right)=\ln F_{i}^{i}\left(x_{i}, \xi\right)-\ln F_{j}^{j}\left(x_{j}, \xi\right)$, it follows that:

$$
\begin{gathered}
\epsilon_{i j}(\mathbf{x})=\left[\frac{F_{j U}^{j}\left(x_{j}, \xi(\mathbf{x})\right)}{F_{j}^{j}\left(x_{j}, \xi(\mathbf{x})\right)}-\frac{F_{i U}^{i}\left(x_{i}, \xi(\mathbf{x})\right)}{F_{i}^{i}\left(x_{i}, \xi(\mathbf{x})\right)}\right] U_{i}(\mathbf{x}) x_{i}-\frac{F_{i i}^{i}\left(x_{i}, \xi(\mathbf{x})\right) x_{i,}}{F_{i}^{i}\left(x_{i}, \xi(\mathbf{x})\right)} \\
=\left[\frac{F_{i U}^{i}\left(x_{i}, \xi(\mathbf{x})\right)}{F_{i}^{i}\left(x_{i}, \xi(\mathbf{x})\right)}-\frac{F_{j U}^{j}\left(x_{j}, \xi(\mathbf{x})\right)}{F_{j}^{j}\left(x_{j}, \xi(\mathbf{x})\right)}\right] \frac{\psi(\mathbf{x}) b_{i}(\mathbf{x})}{\sum_{j} F_{U}^{j}\left(x_{j}, \xi(\mathbf{x})\right)}+\epsilon_{i}(\mathbf{x})
\end{gathered}
$$

where we used the fact that $b_{i}=F_{i}^{i}\left(x_{i}, \xi\right) x_{i} / \psi$. This allows us to compute:

$$
\epsilon_{i j}(\mathbf{x})-\epsilon_{i j}(\mathbf{x})=\left[\frac{F_{h U}^{h}\left(x_{h}, \xi(\mathbf{x})\right)}{F_{h}^{i}\left(x_{h}, \xi(\mathbf{x})\right)}-\frac{F_{j U}^{j}\left(x_{j}, \xi(\mathbf{x})\right)}{F_{j}^{j}\left(x_{j}, \xi(\mathbf{x})\right)}\right] \frac{\psi(\mathbf{x}) b_{i}(\mathbf{x})}{\sum_{j} F_{U}^{j}\left(x_{j}, \xi(\mathbf{x})\right)},
$$

and the average MEC as:

$\bar{\epsilon}_{i}(\mathbf{x})=\left[\frac{F_{i U}^{i}\left(x_{i}, \xi(\mathbf{x})\right) \psi(\mathbf{x})}{F_{i}^{i}\left(x_{i}, \xi(\mathbf{x})\right)}-\frac{\sum_{j \neq i} F_{j U}^{j}\left(x_{j}, \xi(\mathbf{x})\right) x_{j}}{1-b_{i}(\mathbf{x})}\right] \frac{b_{i}(\mathbf{x})}{\sum_{j} F_{U}^{j}\left(x_{j}, \xi(\mathbf{x})\right)}+\epsilon_{i}(\mathbf{x})$.

Once again, $b_{i} \approx 0$ implies $\bar{\epsilon}_{i} \approx \epsilon_{i} \approx \epsilon_{i j}$, and thus that to take the aggregates as given is approximately optimal when market shares are negligible. Notice that $\bar{\epsilon}_{i}=\epsilon_{i}=\epsilon_{i j}$ even when this is not the case if both preferences and the consumption bundle (and then the price vector) are symmetric. Similar results can be shown when preferences are indirectly implicitly additive.

\footnotetext{
${ }^{46}$ This formally assumes that neither the demand own elasticities nor the quantity aggregator are too small.
} 